\title{
Partner Selection in Supplier-Buyer Relationship with Integration of Leadtime Decisions under Demand Uncertainty Situation
}

\author{
Yosi A. Hidayat ${ }^{+1}$, Katsuhiko Takahashi ${ }^{2}$, Katsumi Morikawa ${ }^{3}$, Kunihiro Hamada ${ }^{4}$ \\ Department of Artificial Complex Systems Engineering1,2,3 \\ Department of Social and Environmental Engineering ${ }^{4}$ \\ Graduate School of Engineering,Hiroshima University, Higashi Hiroshima 7397527, JAPAN \\ Email: takahasi@hiroshima-u.ac.jp², kmorikawa@hiroshima-u.ac.jp ${ }^{3}$,hamada@naoe.hiroshima.u.ac.jp ${ }^{4}$ \\ Lucia Diawati ${ }^{5}$, Andi Cakravastia ${ }^{6}$ \\ Department of Industrial Engineering $1,5,6$ \\ InstitutTeknologi Bandung, Bandung 40132, INDONESIA \\ Email: yosi@mail.ti.itb.ac.id ${ }^{+1}$, luci@ganesha.itb.ac.id ${ }^{5}$,andi@mail.ti.itb.ac.id ${ }^{6}$
}

\begin{abstract}
We developed a procurement decision model, which takes into account partner selection and optimal order quantity with the integration of a planned production leadtime operational decision. Leadtime is taken into account in time and cost performance to achieve on-time delivery of a supply chain (SC) system. We contrast the three following original equipment manufacturer (OEM) conditions, (1) longer leadtime to the buyer but at a lower cost for the supplier, so the buyer has to add crashing cost to reduce the leadtime; (2) less leadtime to the buyer but at a higher cost for the supplier; (3) shorter leadtime to the buyer by adding crashing cost to reduce the inventory cost. Taking into consideration the impact of demand uncertainty directly to the buyers, we focus on simultaneous procedures in achieving an optimal solution. Our model considers an objective function consisting of operational costs and lead time decision under integrated supply chain entities (suppliers, sub-assembly manufacturers (OEMs), and buyers). Based on our numerical results, by trading-off inventory cost and leadtime crashing cost, the best possible combinations of partners in fulfilling demand from the market are $\mathrm{B}_{1}-\mathrm{A}_{2}-\mathrm{S}_{2}$ and $\mathrm{B}_{2}-\mathrm{A}_{1}-\mathrm{S}_{3}$. We found that these two combinations give $\$ 141,102.95$ total profit per year to the SC system. We proposed appropriate strategies that could be applied at OEM by considering order arrival timing and leadtime.
\end{abstract}

Keywords: demand uncertainty,optimum leadtime decision, partner selection, supply chain management.

\section{Introduction}

Supply chain management (SCM) is the management of activities that transforms raw materials into intermediate goods and final products, and then delivers those final products to customers. These supply chain activities involve purchasing, manufacturing, distribution, and transportation to market. From an operational perspective, the goal of SCM is to integrate suppliers, manufacturers, warehouses, and stores, so that merchandise is produced and distributed at the right quantities, to the right locations, and at the right time to minimize system-wide cost while satisfying service requirements in the most effective way (Simchi-Levi et al., 2000). Attainment of this goal may be hindered when the appropriate strategic partner decision is separated from important operational decisions due to demand uncertainty, which directly impacts buyers.

${ }^{*}$ Corresponding Author 
Considering the fact that the buyer must build different kind of products to meet anticipated customer demand, and since future demand is usually uncertain, it is difficult to set plans at the right level in procuring the appropriate material. Subsequently, demand uncertainty is one of the most important factors significantly impacting SC performance. Because procurement can only be done once within one period, the optimal procurement lot size should be properly determined. In a probabilistic inventory, the overstock inventory still can be used in the next planning period, so it only impacts the holding cost. While at the end of the selling season, the product's price will be decreased or discounted because of the deterioration of function, model, and technology will be outdated (Hidayat et al., 2009).

In fact, the on-time delivery of an assembly system generally diminishes due to product or component shortages. The cost considered in this situation is the under-stock cost. Shortages often result in losses in production capacity and/or customers' goodwill induced by missed product delivery dates. The primary cause of component shortage is the inherent uncertainty associated with procurement and/or manufacturing leadtimes, which can be attributed to a variety of reasons ranging from unexpected delays in shipping, transportation, and receiving times to variable setup, processing, and inspection times.

In inventory with uncertainty, leadtime can be reduced at an added cost. By reducing the leadtime, customer service and responsiveness to productionschedule changes can be improved and reduction in safety stocks can be achieved. Manufacturers also tend to reduce the total operation cost while trying to satisfy objectives in leadtime and delivery promptness, so that more profit can be attained.

Our model integrates uncertainty in forms of market demand probability information with strategic and operational decisions in a single framework. The model will be able to capture the costs of tactical and/ or operational functions of the supply chain under uncertainty. Optimal leadtime decisions between buyers and original equipment manufacturers (OEMs) that minimize the total amount of items out of stock and inventory holding costs by adding the possibility to reduce them, which is reflected in the leadtime crashing cost, together with optimal procurement, economic order quantity (EOQ), and partner decisions under demand uncertainty are also integrated in our multi-echelon inventory model.

Our purpose is to develop procurement decision regarding strategic partner selection and optimal order quantity with the integration of leadtime operational decisions. Taking into consideration the direct impact of demand uncertainty to buyers, subsequently to the amount of inventory of OEMs as the decoupling point in our SC system, we focus on simultaneous procedures in achieving an optimal solution. Three entities in SC networks (suppliers, subassembly manufacturers (OEMs), and buyers) are integrated into one objective function, maximizing total SC profit, which contrasts leadtime crashing cost versus inventory cost in the total operational cost. Previous studies related to the issues of supplier selection in the supplier-buyer relationship and uncertainties in terms of demand and leadtime in SCM are discussed in Section 2. In Section 3, we state the problem to be addressed which selects appropriate SC partner by considering demand uncertainty and lead time decision and contrasting inventory versus crashing costs. In Section 4, we formulate a mixedinteger linear programming model for integrated strategic partner selection and operational leadtime decision by considering demand uncertainty. We then present and discuss some computational results and analysis in Section 5. Finally, Section 6 highlights the results of the study and discusses the direction for future work.

\section{Literature Review}

There are a significant number of documented studies in the area of operations research and management science in SC that address some of these issues related to partner selection and uncertainty.

In a supplier-buyer relationship, the partner selection process becomes an important strategic decision. Focusing on a single element (buyer only or supplier only) in the SC cannot assure the effectiveness of the network (Croom, 2001). In partner selection, there has been plenty of research since the seminal work by Dickson (1966). Also, Chan et al. (2004) provide a comprehensive review and classification of pricing and inventory coordination problems discussed in the literature of SC. Weber and Current (1993) discussed a multi-criteria analysis for vendor selection. They developed a model for minimizing 
total cost, late deliveries, and supply rejection due to both infrastructure constraints and constraints imposed by the company's policy. Chaudhary et al. (1993) developed a linear programming model for vendor selection with price breaks. Degraeve et al. (2000) reviewed and evaluated a number of vendor selection models, by using the total cost of ownership as a basis for comparison. They obtained the relative efficiency of the models and showed that mathematical programming models outperform rating models by solving all the models for a single real-life dataset of a purchasing problem. Current and Weber (1994) extended the extensive literature in facility location problems to the solution of vendor selection problems. de Boer et al. (2001) provided a comprehensive review of published decision methods for vendor selection and classified them under a framework that takes into account the diversity of purchasing scenarios and covers all phases of the vendor selection process. Most of the research mentioned above only considered the tactical or strategic level in these decisions. Few considered the operational level in this strategic decision.

With regards to uncertainty, Snyder (2006) concluded his research by identifying four research avenues applicable within today's operation research technology. One of the avenues is the multi echelon model. In this avenue, Snyder (2006) stated that there is a need for models that capture the costs of tactical and/or operational functions of the supply chain under uncertainty.

Demand uncertainty is the most obvious and significant source of uncertainty for most systems (Arda and Hennet, 2006). Therefore, managing uncertainty is inevitable for a component that requires sophisticated technology and the manufacturer guarantees that the damage probability of this component is very low for the life of the product. The manufacturer produces only a limited number of components based only on order, and reorder usually is not allowed.

Sabri and Beamon (2000) stated in their research that uncertainty (e.g. customer demands, exchanges rates, travel times, amount of returns in reverse logistics, supply leadtime, transportation costs, and holding costs) is one of the most challenging but important problems in supply chain management.
If a probabilistic behavior is associated with uncertain parameters (either by using probability distributions or by considering a set of discrete scenarios each of which with some subjectivity probability of occurrence), then a stochastic model may be the most appropriate for this situation (Melo et al., 2009). Another modeling possibility arises when some parameters predictably change over time (e.g. demand levels and costs).

Under uncertainty, an overstock product cannot be used in the future because of its life cycle, and its function, model and technology are outdated (Hidayat et al., 2009). In this research, they found that by considering demand uncertainty, the buyer will become more responsive to the market, thus affecting the expected leadtime delivery delay and more able to reduce the risk of under-stock and over stock conditions that impact the expected total cost.

Demand uncertainty with regards to inventory problems also encourages us in integrating this issue in a strategic partner selection decision. Hillier (2002) developed a model for considering purchasing, ordering, inventory, and shortage costs where components are replenished independently according to lot size and reorder point policy.

Ma et al. (2002) developed a multi-period and multistage assembly network model with multiple products and stochastic demands, and proposed a scheme to express the desired base-stock level at each stocking point as a function of the corresponding achieved fill rate. Lin et al. (2006) analyzed the quantitative relationship between leadtime and the inventory level of common components and found efficient ways to determine customization level, optimize inventory management, and lower costs in a multi-period model of component commonality with leadtime.

Mohebbi and Choobineh (2005) studied the impact of introducing component commonality into an assemble-to-order environment when demand is subject to random variations and component procurement orders experience random delays. By using simulated data, they showed that component commonality significantly interacts with demand and SC uncertainties, and the benefits of component commonality are most pronounced when both uncertainties exist.

Nonas (2007) considered the problem of finding the optimal inventory level for components in an 
assembly system where multiple products share common components in the presence of random demand. The inventory problem he considered is modeled as a two-stage stochastic recourse problem where the first stage is to set the inventory levels to maximize expected profit, while the second stage is to allocate components to products after observing demand.

Regarding the issue of leadtime uncertainty in assembly systems, several studies took the dualsourcing technique into consideration when the suppliers' leadtimes are stochastic, but much less research was concerned with the coordination problem in supply leadtime uncertainty. Yano (1987) considered the coordination problem when the supply leadtimes are stochastic for different components in an assembly system. Hopp and Spearman (1993) considered the problem of setting optimal leadtimes in an assembly system where all components are purchased and the only manufacturing operation is the final assembly. They described two formulations of the problem: (1) minimizing total inventory-carrying and tardiness costs and (2) minimizing inventory-carrying costs subject to a service constraint. Hegedus and Hopp (2000) described a practical method for setting safety leadtimes for purchased components in assembly systems with uncertainty in the supply process.

Tang and Grubbstroom (2003) studied a detailed coordination problem in a two-level assembly system with stochastic leadtimes for lower-level items and deterministic demand for the finished item. They found that the optimal safety leadtime is the difference between planned and expected leadtimes. In this research, we enhanced their research in solving the optimal planned leadtimes to minimize the total amount of out-of-stock items/components and inventory holding costs by adding the possibility to reduce them, which is reflected in the leadtime crashing cost, together with optimal procurement, EOQ, and partner decisions under demand uncertainty.

According to our literature studies regarding supplier selection, most of the research mentioned above only considered a tactical or strategic level in their decisions. Few researchers considered the operational level in this strategic decision. $\mathrm{Li}$ and O'Brien (1999) developed a model of the supplierbuyer relationship in a hierarchical way of both strategic and operational levels, but in a sequential flow. In their research, after the partner selection process, then at the operational level, manufacturing and logistics activities were optimized under given targets. We enhanced this sequential flow with a simultaneous one and by adding new factor, demand uncertainty and leadtime decisions.

Regarding leadtime as an operational decision, the previous research only considered leadtime decisions as time unit measurement decisions to achieve on-time delivery performance. They did not integrate leadtime delivery decisions with the total SC cost or profit. We integrated these decisions with the expected total SC cost; which finally affects the total SC profit as the integrated objective function.

\section{Problem Statement}

We assume an SC which comprises a number of component suppliers, sub-assembly manufacturers facilities (OEM facilities), and buyers in different geographical locations and interacting through global marketplaces. We assume a global marketplace for components through which component suppliers sell a variety of components to a sub-assembly manufacturer (OEM). The OEM uses these components in the production of a variety of sub-assemblies in its manufacturing facilities. These sub-assemblies are then sold to buyers through sub-assemblies marketplaces. The buyers can be defined as multinational-sales companies of OEMs or independent distributors. Our SC configuration is shown in Figure 1.

Demand uncertainty as a new factor in this proposed model is affected by customer buying behavior, which is reflected by potential benefits of demand forecasting and its probability to reduce the risk of overstocking or shortage. There are three conditions (two non-ideal and one ideal) that might exist, (1) real demand is more than procurement quantity (under-stock condition exists) (2) real demand is less than procurement quantity (overstock condition exists), and (3) real demand is the same as procurement quantity (no overstock and understock). For achieving a win-win solution among these three conditions, we should find the optimal quoted procurement quantity per year and quoted EOQ per order that maximizes profit by considering demand uncertainty in forms of probability. One of these three 
Figure 1. Supply chain configuration

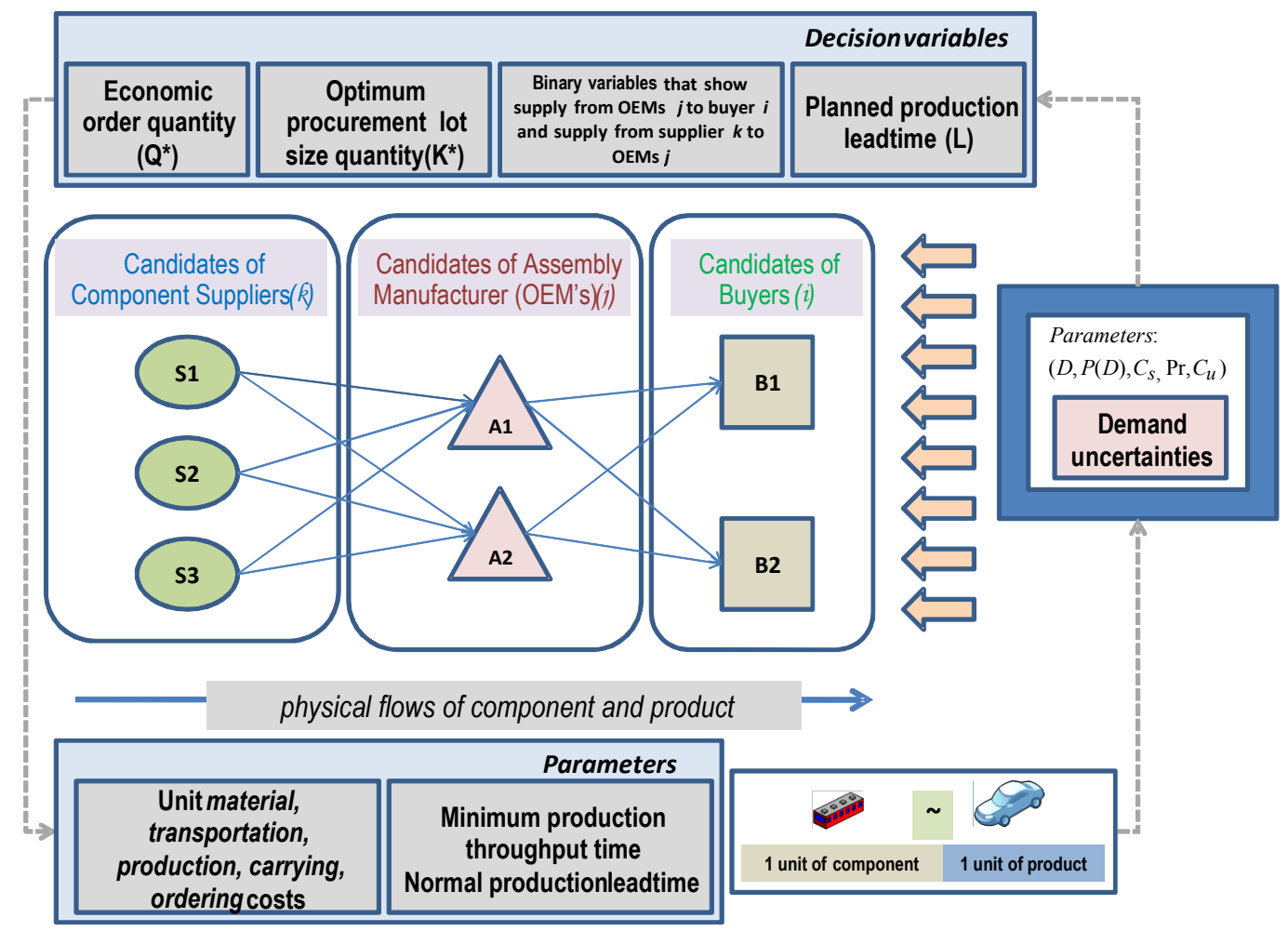

conditions is faced by buyers because of the direct effect of demand uncertainty from the market.

To anticipate leadtime uncertainty among suppliers and contingent orders from buyers, OEMs should act as a product decoupling point. The effort in reducing the leadtime will induce an increase in the crashing cost, but the decrease in leadtime can reduce the safety stock of OEMs. The determination of the optimum leadtime leads to the determination of demand during leadtime and the optimum order quantity. The optimum order quantity will induce the ordering cost, so the change in leadtime leads to a change in inventory and optimum order quantity, and furthermore to the ordering cost.

Our research also integrates the leadtime operational decision that will impact inventory and crashing costs, and finally will be imposed on the total operational cost and the strategic partner selection decision. The basic idea to add this consideration is to get some trade-offs with the following three OEM condition, (1) longer leadtime to the buyer but at a lower cost for the supplier, so the buyer has to add crashing cost to reduce the leadtime; (2) less leadtime to the buyer but at a higher cost for the supplier; (3) shorter leadtime to the buyer by adding crashing cost to reduce the inventory cost.

According to the above situation, we classify two types of stock points that are necessary between OEMs and buyers in our SC structure. Before a product is sold to a buyer, considering the leadtime between OEMs and buyers, OEMs should have some inventory to anticipate contingent orders (counteracted by the demand safety factor) from buyers and some delay from suppliers. Therefore, the safety stock level of OEMs is a function of leadtime. Excess inventories of OEMs for both products and components can be stored and used for the next periods. The holding cost of an OEM product before it is sold to buyers is calculated using Eq. (19). We assume that the leadtime of the supplier to the OEM is zero for components. The holding cost of an OEM component is calculated using Eq. (20).

On the other hand, after the finished product is sold to buyers, it becomes the inventory of these 
buyers. This inventory of buyers is similar to the newsboy inventory problem, where excess inventories are salvaged. There are only overstock and understock costs, calculated using Eqs. (1) to (11). This is due to the fact that a high-technology content product as defined in Hidayat et al. (2009), such as automobiles products, has a distinctive life cycle pattern. Under uncertainty, an overstock product cannot be used in the future because of its life cycle and because its function, model and technology are outdated (Hidayat et al., 2009). This principal is used by buyers in determining the optimal demand lot size by considering the probability of demand, under-stock, and overstock costs.

After deciding the optimal lot sizes, buyers send the order information to the OEMs and later, the OEMs send the information to the suppliers. This flow of information means that buyers do not have inventory stock. Moreover, excess inventories of buyers are salvaged. However, for OEMs and suppliers, excess product and component inventories can be stored and used for the next periods. The number of inventories in OEMs is also induced by the leadtime between buyers and OEMs. In brief, buyers own the overstock and under-stock costs, while OEMs own the inventory holding cost.

Regarding crashing cost, the OEMs inform the buyers of their minimum production throughput time (days) and normal production leadtime (days) for a product. To avoid overstock and under-stock conditions, and also considering demand uncertainty (demand probability from the market), buyers also consider the possibility of shortening the delivery leadtime to fulfil market demand by paying crashing cost. These flows are closed-loop flows. According to the flow of information, the related costs of suppliers, OEMs, and buyers that finally induce the total supply chain profit are developed in our model.

\section{Model Development}

We developed a model for supply chain planning that harnesses the information within global marketplaces. Specifically, we determine the optimal procurement quantities within the selected partner in the downstream and upstream marketplaces and select the SC configuration within marketplaces that will allow us to meet the demand. This decision is based upon the product demand in the downstream marketplaces in the SC after the members of downstream marketplace consider demand uncertainty and leadtime factors from the market and supply of materials in the upstream marketplaces of the SC. In particular, this research will inevitably play an important role in this SC in the context of the global $\mathrm{SC}$ for components and sub-assembly products.

\section{Model Assumptions}

The following assumptions were used in developing our model:

1. The leadtime $L$ is deterministic, and the demand is stochastic.

2. Demand of a product is derived from the market by stochastic conditions with the information of its probability of event.

3. Products and components will be ordered at the beginning of each planning period in one planning horizon. Products decrease at a constant speed, whereas components decrease at a lot size consumed by their supported products.

4. Considering the leadtime between OEMs and buyers, the OEMs should have safety stock to anticipate fluctuant and uncertain demand. In this case, leadtime affects safety stock and finally the inventory cost of the OEMs.

5. After determining the optimal leadtime and optimal order quantity, buyers release orders to OEMs, who in turn release orders to their suppliers. The release orders from the buyers are fixed and contain only the quantity of components and products that will be supplied from the OEMs to the buyers and from the suppliers to the OEMs. There is some leadtime between OEMs and buyers and zero leadtime between OEMs and their suppliers. The existence of leadtime results in the need of product safety stocks in OEMs.

6. A lot-for-lot (L4L) policy is used to determine the sizes of component procurement orders that will be attached to products. This policy is integrated using the concept of a multi- echelon deterministic inventory system.

7. The ordering lot size is fixed for every order.

8. The ordered parts will be supplied at the time of order but will be consumed lot-per-lot.

9. The price of components does not depend on the order lot size (no discounted price).

10. There are no production capacity or storage constraints. 


\section{Model Notations}

By referring to the supply chain structure in Figure 1, together with the model assumptions, we developed a list of parameters and variables in the developed model, as listed in Table 1.

\subsection{Objective Function}

Table 1. Notations and definitions of parameters, variables, and decision variables

\begin{tabular}{|c|c|}
\hline Index & \\
\hline i & Buyer's index $(\mathrm{i}=1,2, \ldots, \mathrm{n})$ \\
\hline j & Assembly component manufacturer's (OEM's) index $\left(\mathrm{J}=1,2, \ldots, 0_{1}\right)$ \\
\hline k & Component supplier's index $\left(k=1,2, \ldots ., u_{i j}\right)$ \\
\hline $\mathrm{t}$ & $\begin{array}{l}\text { Alternatives of demand lot sizes }(t=1,2, \ldots, z), z \text { is maximum demand } \\
\text { lot sizes during planning horizon. }\end{array}$ \\
\hline I & Number of crashing component $(l=1,2, \ldots, w)$ \\
\hline \multicolumn{2}{|l|}{ Parameters } \\
\hline$S$ & Safety factor of demand \\
\hline D & Forecasted market demand (unit/year) \\
\hline$P(D)$ & Probability of demand $D$ \\
\hline$P_{r}$ & Finished product selling price (\$/unit) \\
\hline$C_{m}$ & Component purchasing cost (\$/unit) \\
\hline $\mathrm{C}_{0}$ & Fixed production cost (\$/unit) \\
\hline$C_{r}$ & Transportation cost (\$/unit) \\
\hline $\mathrm{C}_{\mathrm{u}}$ & Buyer's under-stock cost (\$/unit) \\
\hline $\mathrm{C}_{\mathrm{s}}$ & Buyer's overstock cost (\$/unit) \\
\hline$C_{r t}$ & Unit costs reducing production leadtime of component ( $\$ /$ day) \\
\hline $\mathrm{H}_{\mathrm{m}}$ & Unit stock carrying cost of component (\$/time unit) \\
\hline $\mathrm{H}_{\mathrm{f}}$ & Unit stock carrying cost of finished product (\$/time unit) \\
\hline$A_{m}$ & Unit ordering cost of component from OEMs to supplier (\$/order) \\
\hline$A_{f}$ & Unit ordering cost of finished product from buyer to OEMs (\$/order) \\
\hline $\mathrm{PL}_{\min }$ & Minimum production throughput time (days) \\
\hline $\mathrm{PL}_{\text {normal }}$ & Normal production leadtime (days) \\
\hline \multicolumn{2}{|l|}{ Variables } \\
\hline ETC & Expected total cost (\$/year) \\
\hline LCC & Expected leadtime crashing cost (\$/year) \\
\hline $\mathrm{HCM}$ & Total stocks carrying cost of component (\$/year) \\
\hline HCF & Total stocks carrying cost of finished product (\$/year) \\
\hline $\mathrm{EF}(\mathrm{K})$ & Expected profit of buyer when buyer procures $\mathrm{K}$ unit \\
\hline EAM & Total ordering cost of component (\$/year) \\
\hline EAF & Total ordering cost of finished product (\$/year) \\
\hline $\mathrm{F}(\mathrm{K} \longrightarrow \mathrm{D})$ & $\begin{array}{l}\text { Profit pay off if buyer procures } K \text { unit of component, when real } \\
\text { demand is } D \text { units }\end{array}$ \\
\hline r & Reorder point \\
\hline $\mathrm{DL}$ & Expected demand during leadtime \\
\hline
\end{tabular}

\begin{tabular}{|c|c|}
\hline Variables & \\
\hline$s \sigma \sqrt{L}$ & Safety stock level \\
\hline$t^{*}$ & $\begin{array}{l}\text { Optimal lot sizes when demand unit is equal to procurement unit } \\
\text { (ideal condition, no shortage or overstock). In this case, demand } \\
\text { unit equals procurement unit. Otherwise, if } 1 \leq t<t^{*} \text {, then overstock } \\
\text { condition exists, and } t^{*}<t<z \text {, then under-stock condition exists. }\end{array}$ \\
\hline \multicolumn{2}{|l|}{$\begin{array}{c}\text { Decision } \\
\text { Variables }\end{array}$} \\
\hline$b_{j i}$ & Binary variable that shows supply from OEMs $j$ to buyer $i$ \\
\hline$b_{k j}$ & Binary variable that shows supply from supplier $k$ to OEMs $j$ \\
\hline$L$ & Planned production leadtime (time unit) \\
\hline$K^{*}$ & Optimal procurement quantity (unit/year) \\
\hline$Q^{*}$ & Economic order quantity (unit/order) \\
\hline
\end{tabular}

The expected total profit is considered in our model as an integrative objective function to obtain optimal decision variables. This integrated objective function takes into account the expected total operational costs by trading-off inventory and leadtime crashing cost together with the under-stock and overstock costs faced by buyers.

Demand uncertainty, as a new factor in this proposed model, is affected by customer buying behavior that is reflected by potential benefits of demand forecasting and its probability in order to reduce the risk of overstocking or shortage. In this case, potential demand and its probability, costs for material $\left(\mathrm{C}_{\mathrm{m}}\right)$ fixed production $\left(\mathrm{C}_{\mathrm{p}}\right)$ transportation $\left(C_{r}\right)$, under-stock condition $\left(C_{u}\right)$, overstock cost condition $\left(\mathrm{C}_{\mathrm{s}}\right)$, carried materials $(\mathrm{HCM})$, carried finished products $(\mathrm{HCP})$, ordered materials (EAM), ordered finished products (EAF), and leadtime crashing cost (LCC) together with product price $\left(\mathrm{P}_{\mathrm{r}}\right)$ are considered to determine the total expected profit as, shown in Eq. (1).

Equation (1) shows the relationship between total expected profit, expected profit if the buyer procures $K$ units of a component when the real demand is $D$ units, and the probability of demand along the planning period. Subsequently, Eq. (1) is impacted by the operational cost of the SC system. This relationship will interconnect the influence of demand uncertainty and the decision of partner selection. The indexes $i, j, k, t$ indicate that all prices and costs depend on where to produce and from which suppliers the component is supplied. The decisions that show "where to produce" and "from 
where to procure" are indicated in the binary decision variables in Eq. (32), which are related to the strategic partner selection decision.

Objective Function: Maximize

$E F(K)=\sum_{i=1 t=1}^{n} \sum_{t=1}^{z} F\left([K \rightarrow D]_{i}^{t}\right) P\left(D_{i}^{t}\right)$

There are two non-ideal conditions that might exist, (1) real demand is more than the procurement quantity (under-stock condition exists) (2) real demand is less than the procurement quantity (overstock condition exists). Buyers need to find the optimal quoted procurement quantity per year and quoted EOQ per order that maximize the total supply chain profit by considering demand probability. Furthermore, we would like to set the mathematical relationships related to demand uncertainty and related variables. Equations (2) to (11) are related to the determination of optimal quantity to be procured to maximize profit of SC systems.

In a non-ideal condition, whether demand quantity is more or less than the procurement quantity, the excess or shortage of products will affect the expected profit in each combination of situations.

$$
\begin{aligned}
& F\left([K \rightarrow D]_{i}\right)=\sum_{k=1}^{n_{n}} \sum_{i=1}^{n} \sum_{i=1}^{n} \sum_{i=1}^{i-1}\left[\left(\left[\mathrm{rr}_{i}-E T C_{i j k}\right) D_{i}^{\prime}\right\}-\left\{\left(E T C_{j k}-C S_{i}\right) K_{i}^{\prime}\right\}\right] \text { if } D_{i}^{\prime}<K_{i}^{\prime}
\end{aligned}
$$

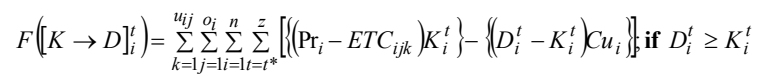

If we consider under-stock cost as $\left(D_{i}^{t}-K_{i}^{t}\right) C$ and overstock cost as $\left(\mathrm{K}_{\mathrm{i}}^{\mathrm{t}}-\mathrm{D}_{\mathrm{i}}^{\mathrm{t}}\right) \mathrm{C}$, then a buyer can estimate the optimal quantity to be procured by comparing the expected total profit that can be gained if he/she decides to procure that quantity, as shown in Eq. (4). This buyer's decision induces the physical and information flow along the SC.

$$
\begin{aligned}
& E F(K)=\sum_{k=1}^{u_{i j}} \sum_{j=1}^{o_{i}} \sum_{i=1}^{n} \sum_{t=1}^{t^{*}-1}\left[\left\{\left(\mathrm{Pr}_{i}-C S_{i}\right) D_{i}^{t}-\left(E T C_{i j k}-C s_{i}\right) K_{i}^{t}\right\} P\left(D_{i}^{t}\right)\right] \\
& +\sum_{k=1}^{u_{i j}} \sum_{j=1}^{o_{i}} \sum_{i=1}^{n} \sum_{t=l^{*}}^{z}\left[\left\{\left(\mathrm{Pr}_{i}-E T C_{i j k}\right) K_{i}^{t}-\left(D_{i}^{t}-K_{i}^{t}\right) C u_{i}\right\} P\left(D_{i}^{t}\right)\right]
\end{aligned}
$$

$E F(K)=\sum_{k=1}^{u_{t j}} \sum_{j=1}^{o} \sum_{i=1}^{n} \sum_{t=1}^{t_{k}^{*}-1}\left(\operatorname{Pr}_{i} D_{i}^{t} P\left(D_{i}^{t}\right)\right)-\left(C S_{i} D_{i}^{t} P\left(D_{i}^{t}\right)\right)-\left(E T C_{i j k} K_{i}^{t} P\left(D_{i}^{t}\right)\right)+\left(C S_{i} K_{i}^{t} P\left(D_{i}^{t}\right)\right)$
$E F\left(K_{i}^{t^{*}+1}\right)-E F\left(K_{i}^{t^{*}}\right)<0$; for $\forall i$

$$
\begin{aligned}
& -\left(E T C_{i j k}-C s_{i}\right)-\left(\mathrm{Pr}_{i}+C u_{i}-C s_{i}\right) \sum_{t=t^{*}+1}^{z} P\left(D_{i}^{t}\right)<0 ; \text { for } \forall i, j, k \\
& \sum_{t=t^{*}+1}^{z} P\left(D_{i}^{t}\right)<\frac{\left(E T C_{i j k}-C s_{i}\right)}{\left(\operatorname{Pr}_{i}+C u_{i}-C s_{i}\right)} ; \text { for } \forall i, j, k
\end{aligned}
$$

$E F\left(K_{i}^{t^{*}-1}\right)-F\left(K_{i}^{t^{*}}\right)<0 ;$ for $\forall i$

$\left(E T C_{i j k}-C s_{i}\right)-\left(\operatorname{Pr}_{i}+C u_{i}-C s_{i}\right) \sum_{t=t^{*}}^{z} P\left(D_{i}^{t}\right)<0 ;$ for $\forall i, j, k$

$\sum_{t=t^{*}}^{z} P\left(D_{i}^{t}\right)<\frac{\left(E T C_{i j k}-C s_{i}\right)}{\left(\operatorname{Pr}_{i}+C u_{i}-C s_{i}\right)} ;$ for $\forall i, j, k$

Equations (7) and (9) lead us to the final conclusion of the probability of the optimal procurement unit by considering related variables, as expressed in Eqs. (10) and (11). Henceforth, the probability value for each alternative of a supplierbuyer combination will be used as the demand uncertainty factor, $\left(\mathrm{P}_{\mathrm{i}}^{\mathrm{t}^{*}}\right)$ and integrated into the material input and product output processes.

$\sum_{i=t^{t}}^{z} P\left(D_{i}^{t}\right)>\frac{\left(E T C_{i j k}-C S_{i}\right)}{\left(\mathrm{Pr}_{i}+C u_{i}-C S_{i}\right)}>\sum_{t=t^{t}+1}^{z} P\left(D_{i}^{t}\right) ;$ for $\forall i, j, k$

$P\left(z \geq K_{i}^{t^{*}}\right)>\frac{\left(E T C_{i j k}-C s_{i}\right)}{\left(\mathrm{Pr}_{i}+C u_{i}-C s_{i}\right)}>P\left(z \geq K_{i}^{t^{*}+1}\right)$ for $\forall i, j, k$

\subsubsection{Detailed Explanation of Cost Components in Determining Total Expected Profit}

The expected total cost is the sum of the material cost, fixed production and transportation costs, components and products holding cost, components and products ordering cost, and leadtime crashing cost for the entire SC. The total relevant cost is denoted by $\operatorname{ETC}\left(Q_{i^{\prime}}, Q_{i j}, L_{i j}\right)$, as shown in Eq. (12).

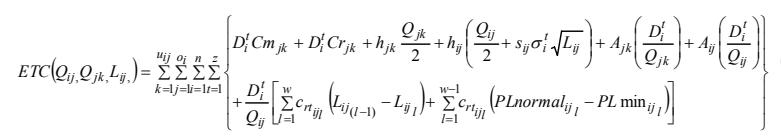




\subsubsection{Variable costs related to time-based measurement}

The total cost components in Eq. (12) consists of two types of cost categories, fixed cost (material, production, and transportation costs) and variable cost (inventory, ordering, and leadtime crashing costs) that are related to time-based measurement (leadtime decision). In this subsection, we explain in more detail the variable costs that are affected by leadtime decision.

Considering that leadtime has $l$ components for each OEM manufacturing facility. The $t^{\text {th }}$ component for each possible buyer $i$ and OEM $j$ combination has a minimum production throughput time $\mathrm{PL}_{\min _{1}}$, normal production leadtime $\mathrm{PL}_{\text {normal, }}$, and a crashing cost per unit time $c_{\mathrm{rtij}}$. The leadtime components are crashed one at a time starting with the component of least $c_{\mathrm{rt}}$. The inter-dependence among the leadtime components may require crashing of more than one component at a time. In many realistic cases, the leadtime components are independent. We assume that there is no interdependence among leadtime components.

Let $L_{\mathrm{ij}_{l}}$ be the length of the leadtime with components $1,2,3, \ldots . w$, which is crashed to their minimum, and then we obtain Eqs. (13) and (14).

$$
\begin{aligned}
& L_{i j_{\min }}=\sum_{l=1}^{w} P L \min _{i j l} \leq L_{i j} \leq \sum_{l=1}^{w} P \text { Lnormal }_{i j l}=L_{i j \max } ; \forall i, j \\
& L_{i j}=L_{i j_{\max }}-\left(\sum_{l=1}^{w-1} P \text { Lnormal }_{i j_{l}}-\text { PL } \min _{i j_{l}}\right) ; \forall i, j
\end{aligned}
$$

The leadtime crashing cost $\operatorname{LCC}\left(\mathrm{L}_{\mathrm{ij}}\right)$ for a given is $\mathrm{L}_{\mathrm{ij}_{1}}<\mathrm{L}_{\mathrm{ij}} \leq \mathrm{L}_{\mathrm{ij}_{1.1}}$ given by Eq. (15).

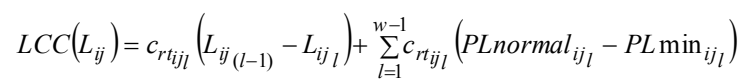

The reorder point is given by Eq. (16), which is related to leadtime decision. $\mathrm{D}_{\mathrm{i}}^{t} \mathrm{~L}_{\mathrm{ij}}$ in Eq. (16) is the expected optimal demand of buyer $i$ during the leadtime consumed by OEM $j$ to deliver products to buyer $i$, and $s_{\mathrm{ijj}} \sigma_{\mathrm{i}}^{\mathrm{t}} \sqrt{\mathrm{ij}}$ in Eq. (16) is the product safety stocks for buyer $i$

$r_{i j}=D_{i}^{t} L_{i j}+s_{i j} \sigma_{i}^{t} \sqrt{L_{i j}} ; \forall i, j, t$

$r_{i j}=$ expected demand during lead time + product safety stock $\left(S S_{i j}\right)$ $S S_{i j}=S S_{i j} x$ (standard deviation of lead time demand);
Where $s_{i j}$ is known safety factor of OEM $j$ for anticipating contingent order from buyer $i$. In determining the optimal safety factor, we use the echelon holding cost concept, shown as Eq. (17).

$s_{i j}=\sqrt{\frac{A_{j k}\left(h_{i j}-h_{j k}\right)}{A_{i j} h_{j k}}}$

To anticipate leadtime and demand uncertainty and avoid production delay, the OEMs in the SC system need some product safety stocks. On the other hand, the leadtime between the OEMs and suppliers is zero. In this case, the OEMs and suppliers do not necessary provide safety stock for components. Subsequently, the inventory consumption pattern of the product from OEMs to buyers and the inventory consumption pattern of the component from suppliers to OEMs are different.

For OEMs, the inventory-carrying cost per year is $h_{i j} I_{i j}\left(Q_{i j}, r_{i j}\right)$, where $I_{i j}\left(Q_{i j} r_{i j}\right)$, is the average on-hand inventory that can be approximated by the average net inventory if the back-order during a replenishment cycle is small or even zero compared with the cycle length. The expected net inventory immediately before and after the receipt of an order of size $Q_{i j}$ is $r_{i j}-D_{i}^{t^{*}}$ and $Q_{i j}+r_{i j}-D_{i}^{t^{*}} L_{i j}$, respectively. If we assume a linear de crease over the cycle, then we obtain Eq. (18).

$I_{i j}^{t}\left(Q_{i j}, r_{i j}\right) \cong \frac{Q_{i j}}{2}+r_{i j}-D_{i}^{t} L_{i j}=\frac{Q_{i j}}{2}+s_{i j} \sigma_{i}^{t} \sqrt{L_{i j}} ; \forall i, j, t$

In developing the inventory cost, we use the concept of a multi-echelon serial inventory system. According to this concept, we assume that one product is produced from one unit of components, which, in turn, is obtained from a supplier. When delivering a batch, all the components are delivered at the same time but consumed per lot. No backorders are allowed. The product will be delivered at the same time based on the order from the buyers and the number of the product will constantly decrease. The above explanations bring us to Eqs. (19) to (23).

$$
\begin{aligned}
& \text { Total stocks carrying cost of products (by OEM) }= \\
& H C F=\sum_{j=1}^{o_{i}} \sum_{i=1}^{n} h_{i j}\left(I_{i j}\left(Q_{i j}, r_{i j}\right)\right) \cong \sum_{j=1}^{o_{i}} \sum_{i=1}^{n} \sum_{t=1}^{z} h_{i j}\left(\frac{Q_{i j}}{2}+r_{i j}-D_{i}^{t} L_{i j}\right) \\
& =\sum_{j=1}^{o_{i}} \sum_{i=1}^{n} \sum_{t=1}^{z} h_{i j}\left(\frac{Q_{i j}}{2}+s_{i j} \sigma_{i}^{t} \sqrt{L_{i j}}\right)
\end{aligned}
$$


Total stocks carrying cost of components (by OEM) $=H C M=$

$\sum_{k=1}^{u_{y}} \sum_{j=1}^{o_{i}} h_{j k}\left(\frac{Q_{j k}}{2}\right)$

Total ordering cost of components $(\mathrm{OEM} \rightarrow$ supplier $)=E A M=$

$\sum_{k=1}^{u_{i}} \sum_{j=1}^{o_{i}} \sum_{t=1}^{z} A_{j k}\left(\frac{D_{i}^{t}}{Q_{j k}}\right)$

Total ordering cost of products (buyer $\rightarrow \mathrm{OEM})=E A F=$

$\sum_{j=1}^{o_{i}} \sum_{i=1}^{n} \sum_{t=1}^{z} A_{i j}\left(\frac{D_{i}^{t}}{Q_{i j}}\right)$

Expected crashing cost $($ buyer $)=L C C\left(L_{i j}\right)=$

$\sum_{j=1}^{o_{i}} \sum_{i=1}^{n} \sum_{t=1}^{z} \frac{D_{i}^{t}}{Q_{i j}}\left[\sum_{l=1}^{w} c_{r_{i j}}\left(L_{i j_{i-1}}-L_{i j}\right)+\sum_{i=1}^{w-1} c_{r t}\left(\right.\right.$ PLnormal $\left.\left._{i j /}-P L \min _{i j /}\right)\right]$

$\frac{\partial E T C\left(Q_{i j}, Q_{j k}, L_{j k}\right)}{\partial Q_{i j}}=\left(\frac{h_{i j}}{2}\right)-A_{i j}\left(\frac{D_{i}^{t}}{Q_{i j}{ }^{2}}\right)-\frac{D_{i}^{t}}{Q_{i j}{ }^{2}}\left[c_{n l l}\left(L_{i i_{(l-1)}}-L_{i_{l}}\right)+\sum_{l=1}^{w-1} c_{r t l}\left(P L n o r m a l_{i j}-P L \min _{i j}\right)\right]=0$

Notice that in Eq. (12), for fixed $\mathrm{L}_{\mathrm{ijk}} \mathrm{ETC}\left(\mathrm{Q}_{\mathrm{ij}} \mathrm{Q}_{\mathrm{j} \mathrm{k}^{\prime}} \mathrm{L}_{\mathrm{ij}}\right)$ is convex in $Q_{i j}$ dan $Q_{j k}$ (see Eqs. (24) and (25)). However, for fixed $Q_{i j}, E T C_{i j k}\left(Q_{i j}, Q_{j k}, L_{i j}\right)$ is concave in $\mathrm{L}_{\mathrm{ij}}$ in the interval $\left(\mathrm{L}_{\mathrm{ij}}, \mathrm{L}_{\mathrm{ij}-1,1}\right]_{\mathrm{j}}$ see Eq. (26)). Therefore, for fixed, the minimum leadtime occurs at the end points of the interval.

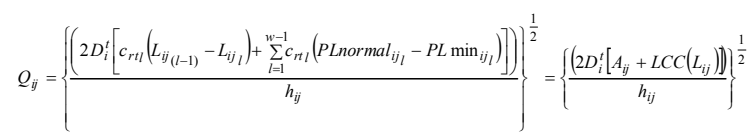

$\frac{\partial E T C\left(Q_{i j}, Q_{j k}, L_{j k}\right)}{Q_{j k}}=0$

$\partial Q_{j k}=\sqrt{\frac{2 A_{j k} D_{i}^{t}}{h_{j k}}}$

$\frac{\partial E T C\left(Q_{i j}, Q_{j k}, L_{j k}\right)}{L_{i j}}=\frac{1}{2} h_{i j} s_{i j} \sigma_{j k} L_{j k}-\frac{1}{2}-\frac{D_{i}^{t}}{Q_{j k}} c_{r t l}=0$

According to these facts, we developed the following procedure for finding optimal $\mathrm{Q}_{\mathrm{j} \mathrm{j}^{\prime}}, \mathrm{Q}_{\mathrm{ij}}$, and $\mathrm{L}_{\mathrm{jk}}$.

(1) For each break point $\mathrm{L}_{\mathrm{ij}}$ in Eq. (14), compute in Eq. (24).

(2) Compute $Q_{j k}$ by using the concept of a serial multi-echelon inventory system in Eq. (25).

(3) Compute the corresponding expected total cost in Eq. (12).
(4) Optimal $Q_{i j^{\prime}} Q_{j k^{\prime}}, L_{i j^{\prime}}$ and will be the values for which the total expected cost is minimum.

\subsubsection{Constraints}

The first constraint in Eq. (27) is related to the optimal leadtime decision that should occur between the cumulative minimum and maximum duration times. This condition guarantees that there is no delay on the SC system.

$L_{i j_{l}}<L_{i j} \leq L_{i j_{l-1}}$

$b_{i j}=0$ or 1

$K_{i j}^{t^{*}} \leq M\left(b_{i j}\right)$

Equations (30) and (31) show that if there is activity in variable $\mathrm{K}_{\mathrm{j} \mathrm{j}^{*}}^{\mathrm{t}^{*}}$ then the value of $\mathrm{b}_{\mathrm{jk}}$ would be 1 . Otherwise, binary variable that shows component supply from supplier $k$ to OEM $j$ to buyer $i\left(b_{\mathrm{jk}}\right)$ would be zero. $M$ indicates a very large number.

$b_{j k}=0$ or 1

$K_{j k}^{t^{*}} \leq M\left(b_{j k}\right)$

Finally, Eq. (32) shows that every stage in the SC can only be supplied from one vendor from the previous stage.

$\sum_{i=1}^{n} \sum_{j=1}^{o_{i}} b_{i j}+\sum_{j=1}^{o_{i}} \sum_{k=1}^{u_{i j}} b_{j k}=1$

\section{Numerical Experiments}

\subsection{Main Numerical Analysis}

To show the effectiveness of the proposed model, we illustrate the above solution procedure using the following example. The problem is solved using the LINGO 8.0 program. The parameter data for operational and strategic decisions are inputted into the program. It is categorized as mixed-integer linear programming. We used the data listed in Tables 2 and 3 for the numerical experiment. Table 2 
Table 2. Data related to demand uncertainty

\begin{tabular}{|c|c|c|c|c|c|c|}
\hline Buyers ( $i$ ) & $t$ & $\begin{array}{l}\text { Demand } \\
\text { Lot Size }\end{array}$ & $\sigma$ & $P(D)$ & $P(z \geq D)$ & $\begin{array}{l}\text { Parameter related to overstock } \\
\text { and under-stock Conditions }\end{array}$ \\
\hline \multirow{6}{*}{1} & $t=1$ & 400 & 4 & 0.3 & 1 & \multirow{6}{*}{$\begin{array}{l}\mathrm{P}_{\mathrm{r}}=\$ 150 / \text { unit } \\
C_{u}=\$ 30 / \text { unit } \\
C_{s}=\$ 50 / \text { unit }\end{array}$} \\
\hline & $t=2$ & 500 & 5 & 0.2 & 0.7 & \\
\hline & $t=3$ & 600 & 6 & 0.2 & 0.5 & \\
\hline & $t=4$ & 700 & 7 & 0.15 & 0.3 & \\
\hline & $t=5$ & 800 & 8 & 0.1 & 0.15 & \\
\hline & $t=6$ & 900 & 9 & 0.05 & 0.05 & \\
\hline \multirow{6}{*}{2} & $t=1$ & 400 & 4 & 0.3 & 1 & \multirow{6}{*}{$\begin{array}{l}\mathrm{P}_{\mathrm{r}}=\$ 152 / \text { unit } \\
C_{u}=\$ 40 / \text { unit } \\
C_{s}=\$ 45 / \text { unit }\end{array}$} \\
\hline & $t=2$ & 500 & 5 & 0.2 & 0.7 & \\
\hline & $t=3$ & 600 & 6 & 0.2 & 0.5 & \\
\hline & $t=4$ & 700 & 7 & 0.15 & 0.3 & \\
\hline & $t=5$ & 800 & 8 & 0.1 & 0.15 & \\
\hline & $t=6$ & 900 & 9 & 0.05 & 0.05 & \\
\hline
\end{tabular}

Table 3. Data for operational and strategic decisions

\begin{tabular}{|c|c|c|c|c|c|c|c|}
\hline Parameters & $\begin{array}{c}\text { Buyer } 1 \\
\text { (B1) }\end{array}$ & $\begin{array}{c}\text { Buyer } 2 \\
\text { (B2) }\end{array}$ & $\begin{array}{l}\text { OEM Facility } 1 \\
\text { (A1) }\end{array}$ & $\begin{array}{l}\text { OEM Facility } 2 \\
\text { (A2) }\end{array}$ & $\begin{array}{l}\text { Supplier } 1 \\
\text { (S1) }\end{array}$ & $\begin{array}{l}\text { Supplier } 2 \\
\text { (S2) }\end{array}$ & $\begin{array}{l}\text { Supplier } 3 \\
\text { (S3) }\end{array}$ \\
\hline$P_{r}$ (\$/unit) & 150 & 152 & - & - & - & - & - \\
\hline $\mathrm{Cu}$ (\$/unit) & 30 & 40 & - & - & - & - & - \\
\hline Cs (\$/unit) & 50 & 45 & - & - & - & - & - \\
\hline \multirow[t]{2}{*}{ A (\$/order) } & - & - & $50\left(B_{1}\right)$ & $100\left(\mathrm{~B}_{1}\right)$ & $150\left(A_{1}\right)$ & $120\left(A_{1}\right)$ & $160\left(A_{1}\right)$ \\
\hline & - & - & $40\left(B_{2}\right)$ & $80\left(B_{2}\right)$ & $140\left(A_{2}\right)$ & $100\left(A_{2}\right)$ & $90\left(A_{2}\right)$ \\
\hline \multirow[t]{2}{*}{ h (\$/unit) } & $50\left(A_{1}\right)$ & $40\left(A_{1}\right)$ & - & - & $20\left(A_{1}\right)$ & $20\left(A_{1}\right)$ & $20\left(A_{1}\right)$ \\
\hline & $60\left(A_{2}\right)$ & $80\left(A_{2}\right)$ & - & - & $40\left(A_{2}\right)$ & $40\left(A_{2}\right)$ & $40\left(A_{2}\right)$ \\
\hline Cm (\$/unit) & - & - & - & - & 5 & 10 & 15 \\
\hline \multirow[t]{2}{*}{$\mathrm{Cr}$ (\$/unit) } & - & - & $2\left(\mathrm{~B}_{1}\right)$ & $3\left(\mathrm{~B}_{1}\right)$ & $2\left(A_{1}\right)$ & $2.5\left(A_{1}\right)$ & $2.5\left(A_{1}\right)$ \\
\hline & - & - & $4\left(\mathrm{~B}_{2}\right)$ & $5\left(B_{2}\right)$ & $2\left(A_{2}\right)$ & $3\left(A_{2}\right)$ & $4\left(\mathrm{~A}_{2}\right)$ \\
\hline $\begin{array}{c}\text { Leadtime } \\
\text { Component from } \\
A_{1} \text { to } B_{1}\end{array}$ & $\begin{array}{l}\text { Normal } \\
\text { Duration } \\
\text { (day) }\end{array}$ & $\begin{array}{l}\text { Minimum } \\
\text { Duration } \\
\text { (day }\end{array}$ & $\begin{array}{c}\text { Unit Crashing Cost } \\
\text { (\$/day }\end{array}$ & $\begin{array}{c}\text { Leadtime } \\
\text { Component from } \\
A_{1} \text { to } B_{2}\end{array}$ & $\begin{array}{l}\text { Normal } \\
\text { Duration } \\
\text { (day) }\end{array}$ & $\begin{array}{l}\text { Minimum } \\
\text { Duration } \\
\text { (day) }\end{array}$ & $\begin{array}{c}\text { Unit Crashing } \\
\text { Cash } \\
\text { (S/day) }\end{array}$ \\
\hline 1 & 16 & 2 & 0.4 & 1 & 15 & 1 & 0.5 \\
\hline 2 & 16 & 2 & 1.2 & 2 & 12 & 5 & 0.9 \\
\hline 3 & 10 & 3 & 5 & 3 & 10 & 3 & 6 \\
\hline $\begin{array}{c}\text { Leadtime } \\
\text { Component from } \\
A_{1} \text { to } B_{1} \\
\end{array}$ & $\begin{array}{l}\text { Normal } \\
\text { Duration } \\
\text { (day) }\end{array}$ & $\begin{array}{c}\text { Minimum } \\
\text { Duration } \\
\text { (day }\end{array}$ & $\begin{array}{c}\text { Unit Crashing Cost } \\
\text { (\$/day }\end{array}$ & $\begin{array}{c}\text { Leadtime } \\
\text { Component from } \\
A_{1} \text { to } B_{2}\end{array}$ & $\begin{array}{l}\text { Normal } \\
\text { Duration } \\
\text { (day) }\end{array}$ & $\begin{array}{c}\text { Minimum } \\
\text { Duration } \\
\text { (day) }\end{array}$ & $\begin{array}{c}\text { Unit Crashing } \\
\text { Cash } \\
\text { (S/day) }\end{array}$ \\
\hline 1 & 24 & 10 & 1 & 1 & 15 & 1 & 0.2 \\
\hline 2 & 16 & 2 & 1.2 & 2 & 11 & 4 & 3 \\
\hline 3 & 9 & 2 & 3.5 & 3 & 9 & 2 & 5 \\
\hline
\end{tabular}

The results from our developed model are listed in Table 4 and in Figs. 2 to 4.

represents the data related to the market and to demand uncertainty. Table 3 represents the data related to operational and strategic decisions among SC members.
According to the numerical results listed in Table 4, the best buyer-OEM-supplier combinations that maximize the total SC profit are $\mathrm{B}_{1}-\mathrm{A}_{2}-\mathrm{S}_{2}$ and $\mathrm{B}_{2}-\mathrm{A}_{1}$ $S_{3}$. This is a global and integrated decision after 
Table 4. Numerical results

\begin{tabular}{|c|c|c|c|c|c|c|c|c|c|c|c|c|}
\hline Conbinations & B1-Al-S1 & B1-A2-S1 & B2-Al-S1 & $\mathrm{B} 2 \mathrm{~A} 2 \mathrm{~S}-\mathrm{S1}$ & B1-Al-S2 & B1-A2-S2 & B2-A1-S2 & $B 2-A 2-52$ & B1-Al-S3 & B1-A2-S3 & B2-A1-S3 & B2-A2-S3 \\
\hline Fingd cost (\$year) & 7200 & 8400 & 7000 & 8000 & 6900 & 8400 & 6750 & 8000 & 6300 & 8400 & 6250 & 8000 \\
\hline Varable cost before considering LT decision (Syear) & 6001.98 & 7564.89 & 4454.73 & 6887.94 & 5551.20 & 6669.09 & 41117.97 & 6213.10 & 646456 & 6142.02 & 4559.34 & 6024.09 \\
\hline Variable cost after considering LT decision (S/year) & 4996.69 & 6630.85 & 3844.98 & 5635.44 & 4699.21 & 6027.68 & 3593.20 & 5635.44 & 5899.96 & 5092.20 & 3923.19 & 5494.13 \\
\hline Profit before considering LT decision (\$/year) & 76531.00 & 7381291 & 64320.00 & 60948.15 & 77306.32 & 74741.27 & 64927.20 & 61643.47 & 77283.34 & 74953.25 & 64959.04 & 61838.22 \\
\hline Profit after considering LT decision (\$year) & 77627.46 & 74818.55 & 64996.05 & 61740.34 & 78249.10 & 75439.13 & 65510.75 & 62257.83 & 78427.55 & 75580.83 & 65663.82 & 62402.77 \\
\hline Percentage of reduced cost & $16.75 \%$ & $12.35 \%$ & $13.69 \%$ & $18.18 \%$ & $15.53 \%$ & $9.62 \%$ & $12.74 \%$ & $9.30 \%$ & $8.89 \%$ & $17.09 \%$ & $13.95 \%$ & $8.80 \%$ \\
\hline Percentage of increased profit & $1.43 \%$ & $1.36 \%$ & $1.05 \%$ & $2.15 \%$ & $1.22 \%$ & $0.93 \%$ & $0.90 \%$ & $1.00 \%$ & $1.48 \%$ & $0.84 \%$ & $1.08 \%$ & $0.91 \%$ \\
\hline \multicolumn{13}{|l|}{\begin{tabular}{|l|} 
Decision variables \\
\end{tabular}} \\
\hline Optimnl procurement quantity (unit/year) & $600(\mathrm{STD}=6)$ & $600(\mathrm{STD}=6)$ & $500(\mathrm{STD}=5)$ & $500(\mathrm{STD}=5)$ & $600($ STD $=0)$ & $600($ STD $=0)$ & $500(\mathrm{STD}=5)$ & $500(\mathrm{STD}=5)$ & $600($ STD $=0)$ & $600($ STD $=6)$ & $500(\mathrm{STD}=5)$ & $500(\mathrm{STD}=5)$ \\
\hline Econonic orderquantiry of conponent (unit/order) & 134.16 & 94.87 & 122.47 & 83.66 & 120.00 & 77.46 & 109.54 & 70.71 & 138.56 & 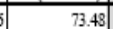 & 126.49 & 67.08 \\
\hline Econonic order quantity of product (unit order) & 41.68 & 55.73 & 36.50 & 36.02 & 41.68 & 55.73 & 36.50 & 36.02 & 41.68 & 55.73 & 36.50 & 36.02 \\
\hline Leadtime (before considering crashing cost)(weeks) & 6 & 7 & 5 & 5 & 6 & 7 & 5 & 5 & 6 & 7 & 5 & 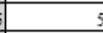 \\
\hline Optimumleadtime (afer considering crashing cost) (weeks) & 2 & 5 & 3 & 2 & 2 & 3 & 3 & 2 & 2 & 2 & 2 & 2 \\
\hline
\end{tabular}

considering demand uncertainty, under-stock and overstock conditions of buyers in response to market demand, and also inventory costs versus leadtime crashing cost. For $\mathrm{B}_{1}-\mathrm{A}_{2}-\mathrm{S}_{2}$, even though the $\mathrm{S}_{2}$ has a higher cost (from the high fixed cost of this combination), reducing the leadtime from seven to three weeks has significantly reduced inventory cost of products, compared with adding a small crashing cost. This combination is a typical decision in choosing OEMs with less leadtime to buyers but at a higher cost for the supplier.

Figure 2. Inventory patterns of products and components

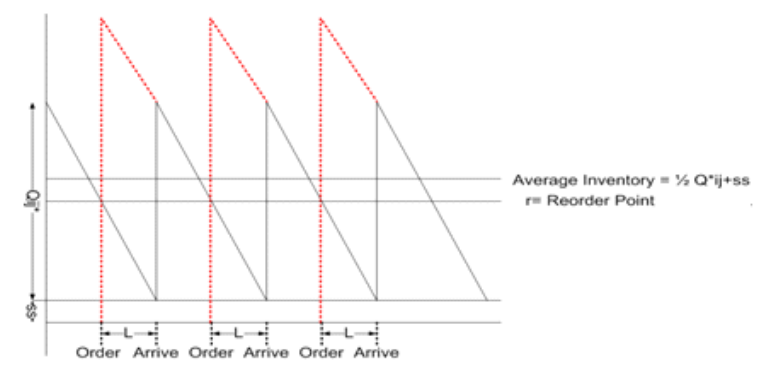

Figure 2(a). Product inventory patterns in OEMs

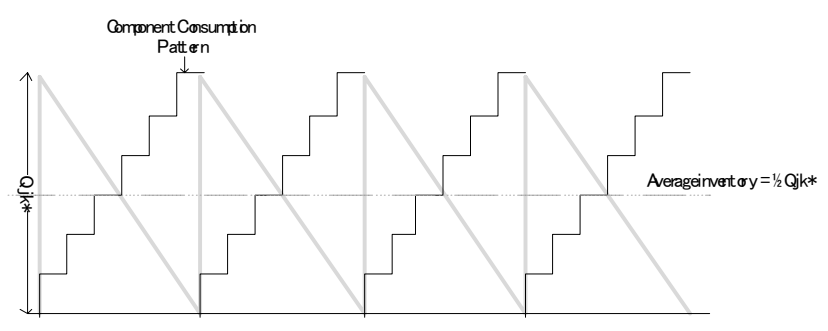

Figure 2(b). Component inventory patterns (black line) and component consumption patterns (grey line) in OEMs
For $\mathrm{B}_{2}-\mathrm{A}_{1}-\mathrm{S}_{3}$, reducing the leadtime from five to two weeks has reduced inventory cost of products, which is balanced by the crashing cost. The lower fixed cost of this combination mostly contributed to the profit. This combination is a typical decision in choosing OEM with shorter leadtime to buyers by adding crashing cost to reduce the inventory cost of OEM. These two combinations results in a profit of $\$ 141,102.95$ per year to the SC system

Fig. 2 shows the inventory patterns of products by buyer and components by OEMs. OEMs have some amount of safety stocks of products that depend on the leadtime decision (see Fig. 2(a)), where OEMs only have carrying cost for their components, which is not affected by the leadtime decision (see Fig. 2 (b)).

From Figs. 3 and 4, we can see the proportion and contribution of fixed and variable costs.

By reducing the leadtime for variable costs, the inventory cost of a product decreases by adding crashing cost. Overall, by considering the optimal leadtime decision, the total variable costs are reduced for every combination of buyer-OEM-buyer. The effectiveness of our model in terms of reducing variable cost is shown in Figure 4 (d).

\subsection{Sensitivity Analysis}

According to Table 2 in sub-section 5.2, we choose small numbers $(1 \%)$ of demand deviations to give some insights on the significant effects of small demand deviation into optimal leadtime and safety stock decisions of OEMs. While determining the optimal procurement lot size of buyers, however, the demand deviation does not affect more than the probability of demand events.

Also, our parameter setting and some key parameter values have shown a significant difference 
Figure 3. Contribution of fixed costs

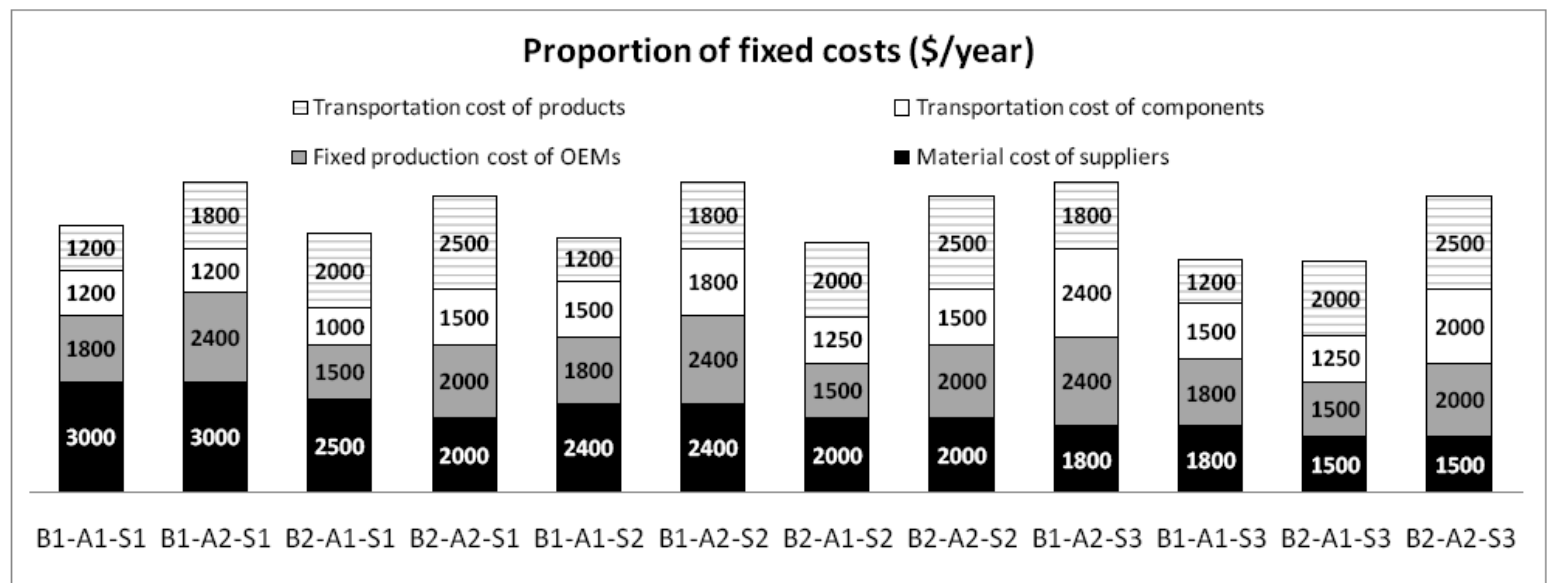

Figure 4. Contribution of variable costs

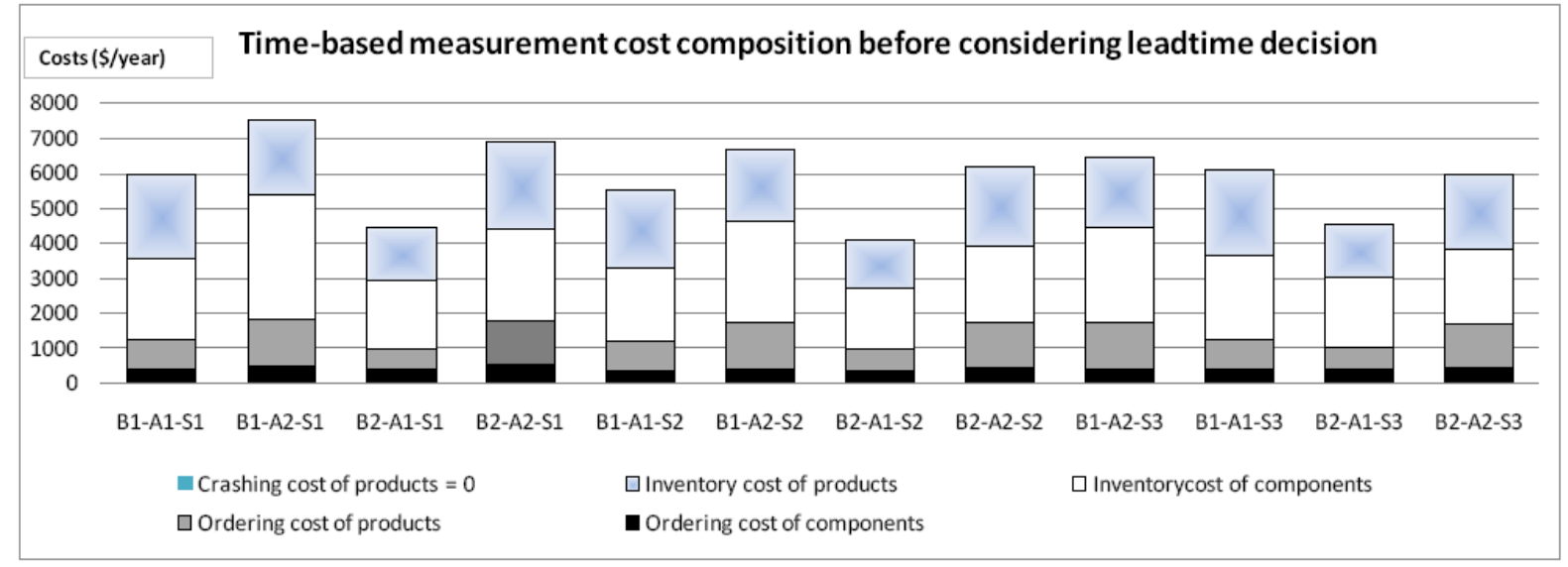

Figure 4(a). Contribution of variable costs before considering leadtime decision

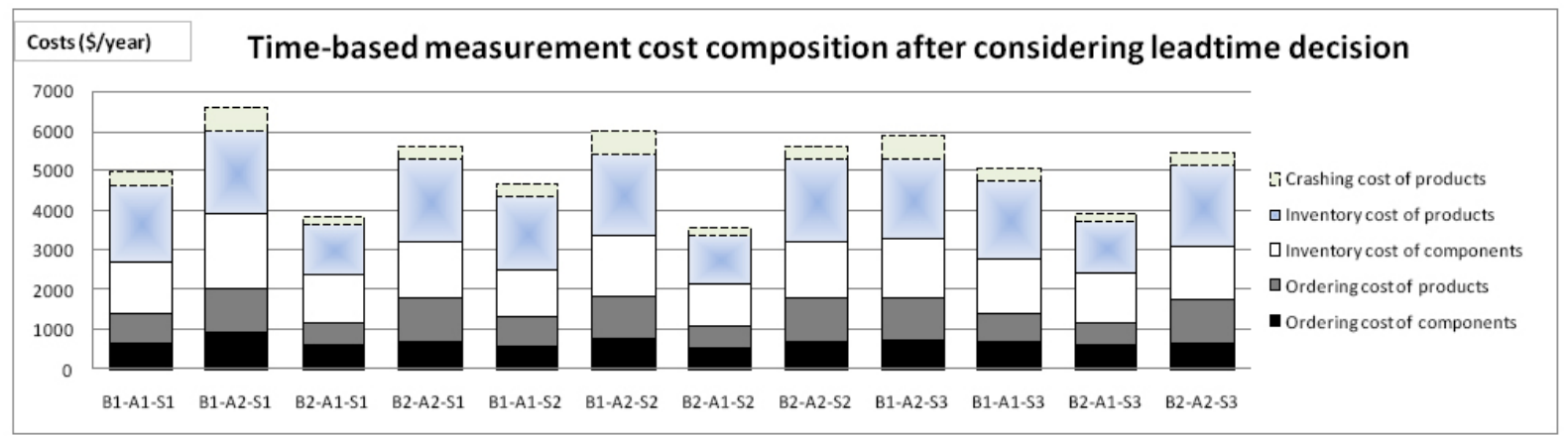

Figure 4(b). Contribution of variable costs after considering leadtime decision 


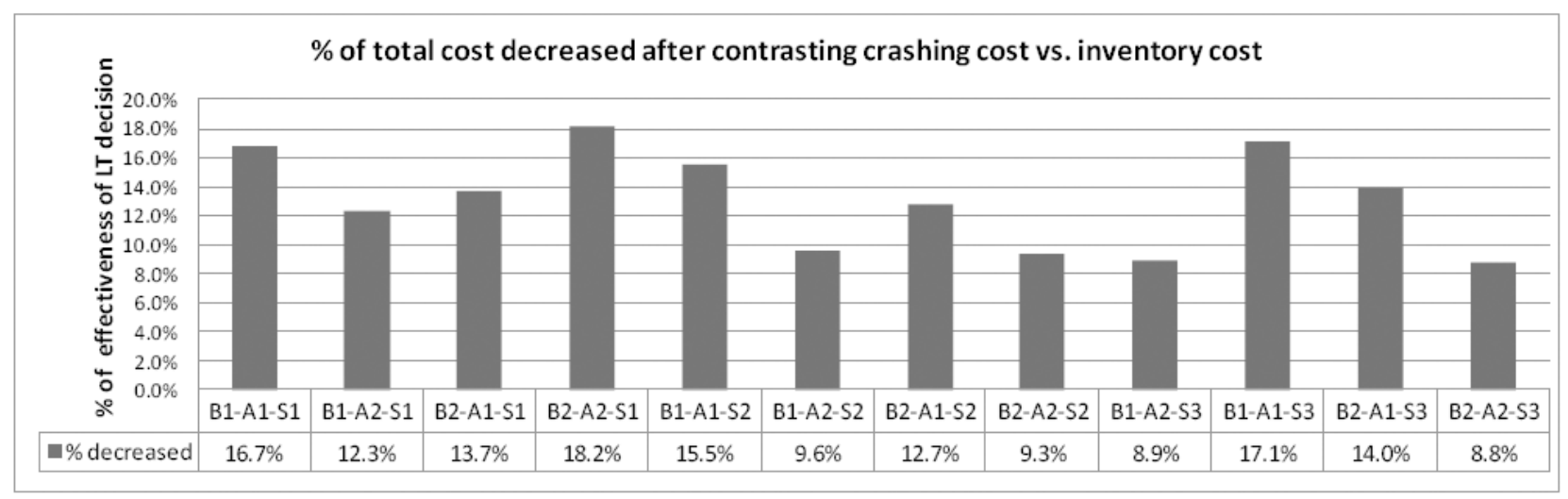

Figure 4(c). Recapitulation of total variable cost improvement before and after considering leadtime decision

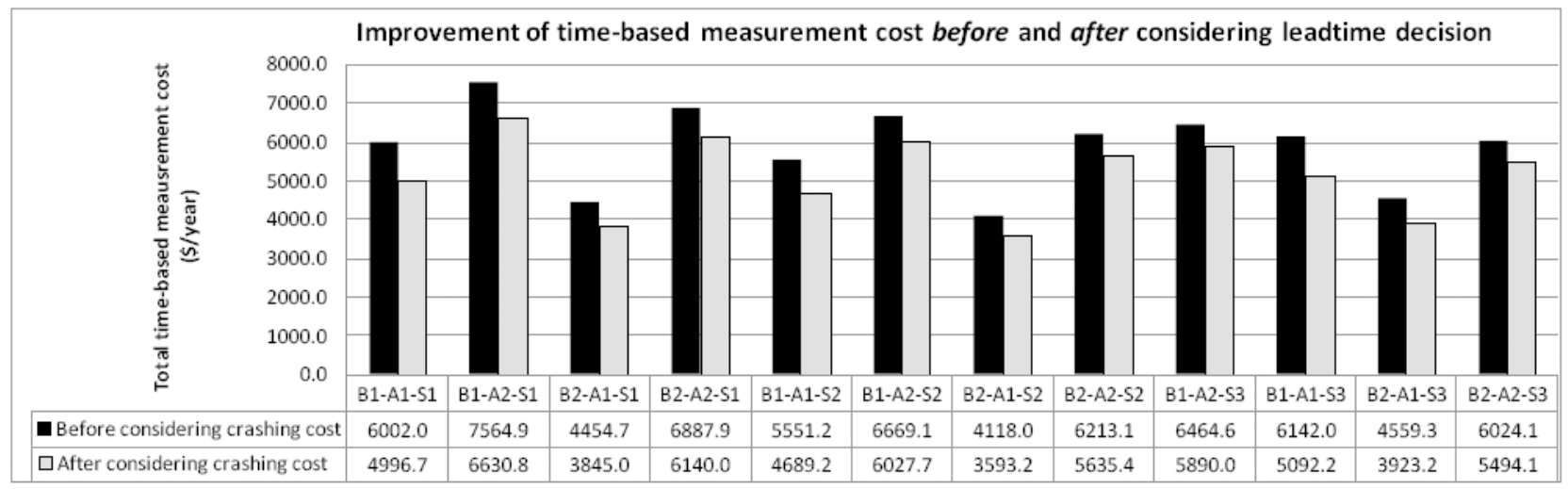

Figure 4(d). Model effectiveness (improved on average by $13.1 \%$ on average of operational process productivity) for all partner combinations

between "before and after" considering leadtime and demand uncertainties. In this sub-section, we explore a more fluctuating standard deviation of demand to show a more significant benefit. The results were obtained from a larger standard deviation of mean demand up to $30 \%$. These sensitivity analysis results are shown in Fig. 5, and the details are attached in the Appendix.

Figures 5(a) and 5(b) show that the greater the demand deviates, the component ordering cost increases insignificantly, while the product ordering cost, and the component and product inventory costs decrease significantly. A significant decreases in OEM product-inventory cost needs to occur reduce leadtime and the later increase in crashing cost. After demand deviates more than $10 \%$ from the mean demand, optimum leadtime decisions are changed and the leadtime should be minimized. The crashing cost only contributes $2 \%-9 \%$ of the total variable costs. As the demand deviation increases, the contribution of crashing cost to variable cost decreases. For the $\mathrm{B}_{2}$ $\mathrm{A}_{1}-\mathrm{S}_{3}$ combination, the contribution of crashing cost starts to decrease after $3 \%$ of demand deviation. This indicates that $\mathrm{B}_{2}-\mathrm{A}_{1}-\mathrm{S}_{3}$ is a typical decision in choosing shorter OEM leadtime by adding the crashing cost to reduce OEM inventory cost.

From the composition of variable and fixed costs and the proportion of crashing cost to the total variable cost, $\mathrm{B}_{1}-\mathrm{A}_{2}-\mathrm{S}_{2}$ is a typical decision in choosing the least amount of leadtime of OEMs but at a higher cost for the suppliers. Another finding is that $\mathrm{B}_{1}-\mathrm{A}_{2}-\mathrm{S}_{2}$ and $\mathrm{B}_{2}-$ $\mathrm{A}_{1}-\mathrm{S}_{3}$ are always the best combinations for maximizing total profit to the SC system. This means that our model always achieves a global optimum solution. 
Figure 5. Contribution of variable costs

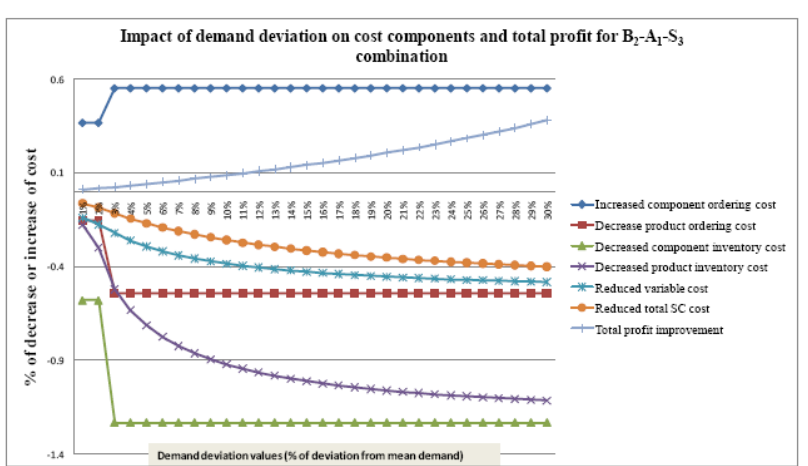

Fig. 5(a) Impact of demand deviation on component cost and total SC profit for $\mathrm{B}_{2}-\mathrm{A}_{1}-\mathrm{S}_{3}$ combination

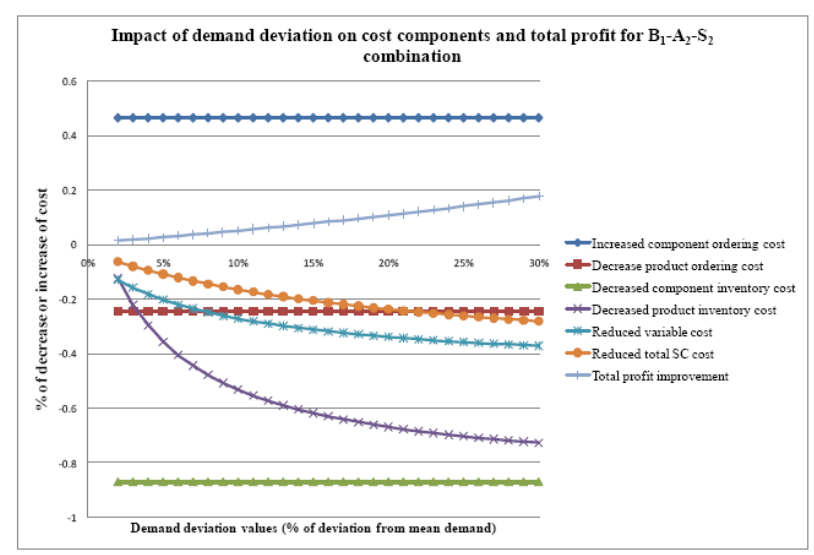

Fig. 5(b) Impact of demand deviation on component cost and total SC profit for $\mathrm{B}_{1}-\mathrm{A}_{2}-\mathrm{S}_{2}$ combination

\subsection{Managerial Insights}

For sensitivity analysis, we investigated the impact of changing demand uncertainty values together with changing safety factor values. We assume that the safety factor value is a positive integer that shows the replenishment of stock between products and components related to the single serial multiinventory system; while the demand uncertainty value is the probability related to the supply of finished-product stocks to fulfill the market's demand (uncertainty outbound SC). We set up three sensitivity-analysis scenarios to determine the effects of safety factor and demand probability parameters. The sensitivity analysis data are summarized in Table 5. For the concept of leadtime in Fig. 2, the analysis of results will be analyzed based on the appropriate strategy applied by manufacturing facilities for each condition by considering the uncertainty of order arrival, as shown in Fig. 6.

To Observe the sensitivity of some parameters in the model, we change some of the demand uncertainty values (indicated as $\mathrm{P}(\mathrm{z}>D)$ ) and safety factor that impacts the leadtime of components and products. This analysis is used for studying the appropriate production strategy to be applied in several demand uncertainty situations.

According to Axsater (2000), the safety factor is strongly affected by the value of $\frac{A_{i j}}{h_{i j}-h_{j k}}$ and $\frac{A_{j k}}{h_{j k}}$. If $\frac{A_{i j}}{h_{i j}-h_{j k}} \geq \frac{A_{j k}}{h_{j k}}$, we should use the same batch size for both products and components, and consequently, each time we produce a batch of components, it should be immediately used for product production. This implies that we do not need any stock of components and that our two-stage system of supplier-OEM and OEM-buyer can be replaced by a single-stage system. This condition is also sufficient in the case of time-varying demand of a product and will become important in the leadtime decision.

In this analysis, we want to synergize our findings with a practical situation in each stage or point of event where uncertainties occur. We discuss this qualitatively (see Fig. 6) in the following paragraphs.

Figure 6. Sensitivity analysis point of view

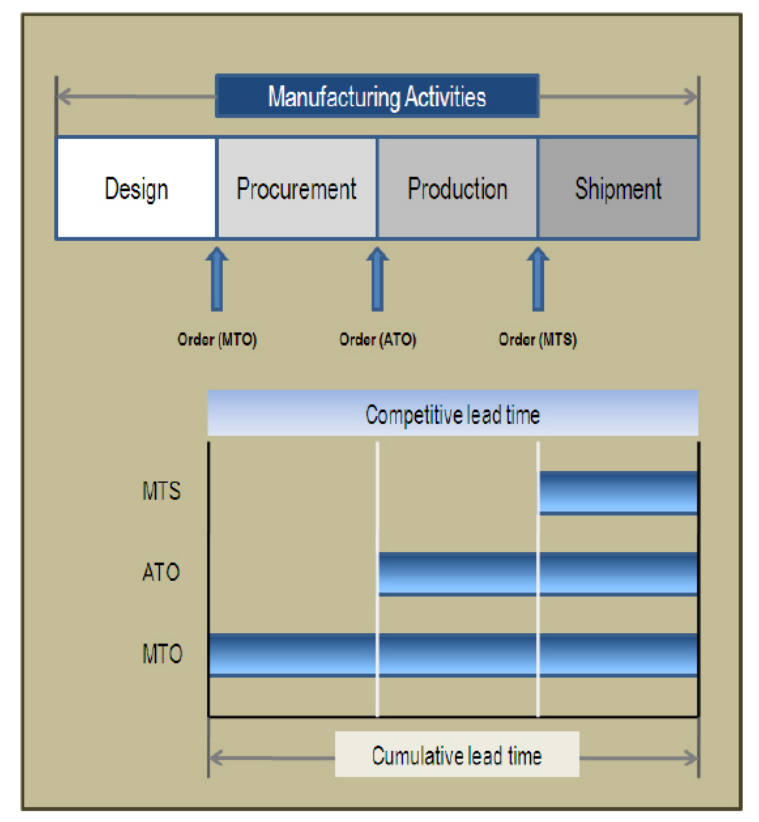


Based on Fig. 6, which is related to the common manufacturing strategy characteristics, when the order has a high probability of arriving before the procurement (material supply) process, the best manufacturing strategy is make-to-order (MTO). In our model, this condition also strengthens the procurement probability of components.

When the order has a high probability of arriving between the procurement (material supply) and production (product manufacturing) processes, the best manufacturing strategy is assembled-toorder (ATO).

Subsequently, when the order has a high probability of arriving between production (product manufacturing) and shipment (product output) processes, the best manufacturing strategy is maketo-stock (MTS). In our model, this condition strengthens the procurement probability of products. We determined the expected profit of each benefit or loss by using one of these strategies in the beginning of our model by taking into account demand uncertainty.

Furthermore, we would like to observe the impacts of leadtime to the total performance criteria that are directly affected by demand uncertainty and safety factor values on the appropriate manufacturing strategy for all alternatives of partner combinations. The results are shown in Figs.7 to 9.

According to Table 5, we choose and vary the demand uncertainty values, procurement probability of components and procurement probability of products to investigate their impact on the chosen strategy (MTO, ATO, or MTS). We use all model equations to evaluate the appropriate strategy. When one of the values is fixed, the other two are varied.

According to the numerical results, the cost components mostly impacted by these parameterranging values are the inventory costs of component and products. Subsequently, these cost components significantly contribute to total SC profit performance.

Based on the results of the first scenario (see Fig. 7), when the safety factor is at a lower level, OEM manufacturing facilities should apply the MTS strategy. This is shown by the slightly higher product inventory cost compared to material inventory cost. In contrast, when the safety factor is at a higher level, OEM manufacturing facilities should apply the MTO strategy. From the supply delay point of view, this MTO strategy will reduce any waste in stock costs at a longer leadtime. A constantly increasing convex shape from the leadtime and inventory cost curves for both component and products show that along with the increasing values of demand uncertainties and safety factor, manufacturers tend to change their strategy from MTS to MTO.

In the second scenario, we applied different values of $\frac{A_{j k}}{h_{j k}}$ and $\frac{A_{i j}}{h_{i j}-h_{j k}}$ for determining the safety factor. When the value of $\frac{A_{j k}}{h_{j k}}$ is lower than the value of $\frac{A_{i j}}{h_{i j}-h_{j k}}$ (see Fig. 8), OEM manufacturing facilities should apply the ATO strategy. This is shown as a slightly different risk contribution of

Table 5. Sensitivity analysis data

\begin{tabular}{|c|c|c|c|c|c|}
\hline \multirow[b]{2}{*}{$\begin{array}{l}\text { Demand probability } \\
\text { value (Scenario I, II, III) }\end{array}$} & \multirow{2}{*}{$\begin{array}{c}\text { Scenario I } \\
\text { Total safety factor with equal } \\
\text { value of } \frac{A_{j k}}{h_{j k}} \text { and } \frac{A_{i j}}{h_{i j}-h_{j k}}\end{array}$} & \multicolumn{2}{|c|}{ Scenario II } & \multicolumn{2}{|c|}{ Scenario III } \\
\hline & & $\begin{array}{l}A_{j k} \\
h_{j k}\end{array}$ & $\frac{A_{i j}}{h_{i j}-h_{j k}}$ & $\begin{array}{c}A_{j k} \\
h_{j k}\end{array}$ & $\frac{A_{i j}}{h_{i j}-h_{j k}}$ \\
\hline 0.05 & 0.2 & 0.70 & 0.97 & 0.95 & 0.80 \\
\hline 0.15 & 0.6 & 0.50 & 0.92 & 0.85 & 0.50 \\
\hline 0.30 & 1.0 & 0.30 & 0.85 & 0.55 & 0.40 \\
\hline 0.50 & 1.4 & 0.15 & 0.75 & 0.35 & 0.15 \\
\hline 0.70 & 2.0 & 0.05 & 0.50 & 0.15 & 0.05 \\
\hline
\end{tabular}


Figure 7. Results of Scenario I

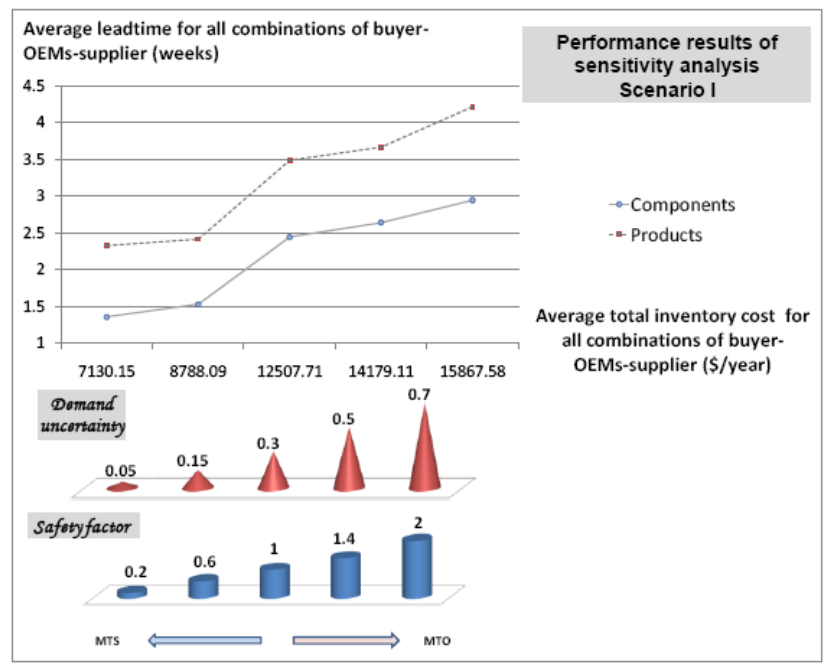

inventory costs of both components and products, instead of increasing leadtime. However, when demand uncertainty $(\mathrm{P}(\mathrm{z}>D)$ is high, MTS is the best strategy. This is due to a sharp increase in the inventory cost of products compared with that of components.

A constantly increasing convex shape from the curve for components and products shows that along with increasing demand uncertainty values and

Figure 8. Results of Scenario II

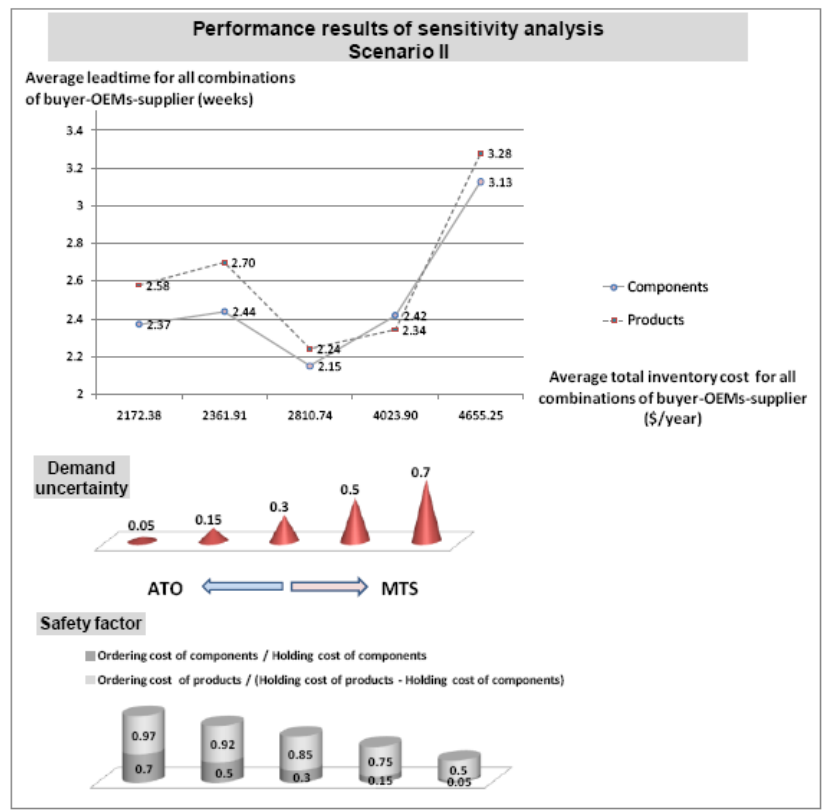

decreasing safety factors (where the value of $\frac{A_{j k}}{h_{j k}}$ is lower than the value of $\left.\frac{A_{i j}}{h_{i j}-h_{j k}}\right)$, OEM facilities tend to change their strategy from ATO to MTS.

In the third scenario, when the value of $\frac{A_{j k}}{h_{j k}}$ is higher than the value of $\frac{A_{i j}}{h_{i j}-h_{j k}}$ (see Fig. 9), the MTO strategy is better than MTS for OEM manufacturing facilities. This is due to the fact that the increase in $\frac{A_{j k}}{h_{j k}}$ makes the material stocks in the manufacturer ineffective. Therefore, non-stock strategies with an acceptable leadtime may be better than the MTS strategy. The MTS strategy will perform better performance than MTO in situations of higher demand uncertainty of products that will affect the higher leadtime. The pure concave shapes from the components and products curves show that along with increasing demand uncertainty values and decreasing safety factors in this situation (where the value of $\frac{A_{j k}}{h_{j k}}$ is higher than the value of $\left.\frac{A_{i j}}{h_{i j}-h_{j k}}\right)$, manufacturers tend to change their strategy drastically from MTO to MTS.

From these three scenarios, the expected total inventory costs for both components and products

Figure 9. Results of Scenario III

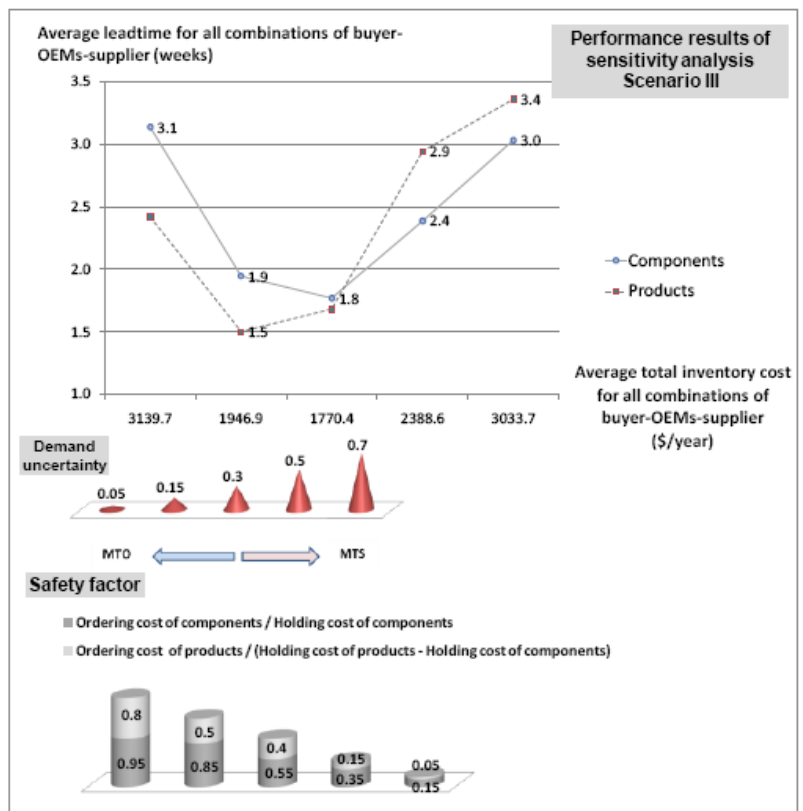


and the length of leadtime will generally be strongly affected while demand uncertainty $(\mathrm{P}(\mathrm{z}>D)$ is at a high level. This general finding of this research is summarized in Fig. 10. As a result, the increase in leadtime and higher inventory conditions makes the suggested strategy superior under a given condition

Figure 10. Results summary

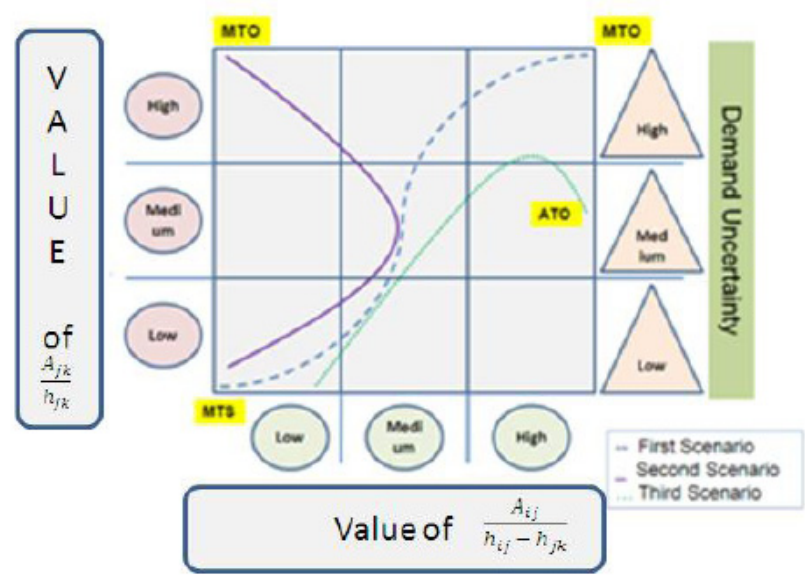

\section{Conclusions and Future Works}

We proposed a mathematical model for considering demand uncertainty, under-stock and overstock conditions of buyers in response to market demand, inventory costs versus leadtime crashing cost into one integrated and simultaneous partner, optimal procurement quantity, and leadtime decisions in a multi-echelon inventory SC system.

To anticipate demand and leadtime uncertainty and avoid delay, OEMs, as decoupling points in our SC model need some amount of product safety stocks. The inventory pattern of products and the consumption pattern of components have different patterns.

The numerical result showed that leadtime decision affects the OEM's product safety stock. This safety stock leads to an EOQ decision that impacts inventory and ordering costs. By trading-off inventory and leadtime crashing costs, the best possible combinations of partners in fulfilling demand from the market are $\mathrm{B}_{1}-\mathrm{A}_{2}-\mathrm{S}_{2}$ and $\mathrm{B}_{2}-\mathrm{A}_{1}-\mathrm{S}_{3}$. We analyzed the trade-off characteristics of each combination. $\mathrm{B}_{1}-\mathrm{A}_{2}-\mathrm{S}_{2}$ is a typical decision in choosing the least amount of leadtime of OEMs but at a higher cost for the supplier, while $\mathrm{B}_{2}-\mathrm{A}_{1}-\mathrm{S}_{3}$ is a typical decision in choosing a shorter leadtime of OEMs by adding crashing cost to reduce the inventory cost of OEMs. These two combinations give a total profit $\$ 141,102.95$ per year to SC systems.

In practical situations, strategy analyses are used in sensitivity analysis, which gives managerial insights into OEM operation strategy while facing leadtime and order arrival uncertainties.

Future research can be extended by considering supply uncertainty in forms of procurement probability, which is the probability related to the supply of material components from suppliers to OEMs and finished products from OEMs to buyers (uncertainty inbound SC) and dynamic pricing between SC members.

\section{References}

Arda, Y. and Hennet, J-C. (2006). Inventory control in a multisupplier system. Int. J. Production Economics, 104 (2), pp. 249-259.

Axsater, S. (2000). Inventory Control: International Series in Operations Research and Management Science, Kluwer Academic Publishers, Boston/Dordrecht/London, pp. 115-169.

de Boer, L., Labro, E. and Morlacci, P. (2001). A review of methods supporting supplier selection. Purchasing and Supply Management, 7, pp. 75-89.

Chan, L. M. A., Shen, Z. J. M., Simchi-Levi, D. and Swann, J. (2004). Handbook of Quantitative Supply Chain Analysis: Modelling in the e-nusiness era (eds) D. Simchi-Levi, SD Wu, Z.J.M. Shen, MA: Kluwer Academic, Boston 'Coordination of pricing and inventory decisions: a survey and classification, pp. 335-392.

Chaudhry, S. S., Frost, F. G. and Zydiak, J. L. (1993). Vendor selection with price break. European J. Operations Research, 70, pp. 52-66.

Croom, S. (2001). Restructuring supply chains through information channel innovation. Int. J. Operations and Production Management, pp. 504-527.

Current, J. R. and Weber, C. A. (1994). Application of facility location modeling constructs to vendor selection problems. European J. Operations Research,76, pp. 387-392.

Degraeve, Z., Labro, E., and Roodhooft, F. (2000). An evaluation of vendor selection methods from a total cost of ownership perspective. European J. Operations Research, 125, pp. 34-58.

Dickson, G. W. (1966). An analysis of vendor selection systems and decisions. Journal of Purchasing, 2 (1), pp. 5-17. 
Hegedus M. G. and Hopp W. J. (2001). Setting procurement safety leadtimes for assembly systems. International Journal of Production Research, 39(15), pp. 3459-3478(20).

Hidayat, Y. A., Takahashi, K., Diawati, L., and Cakravastia, A. (2009). Supply chain strategy for high technologycontent product and its consequences to technology transfer mechanism. Int. J. Intelligent Systems Technologies and Applications, 6 (3/4), pp. 296-308.

Hillier, M. S. (2002). The costs and benefits of commonality in assemble-to-order system with a (Q. r)-policy for component replenishment. European Journal of Operational Research, 141, pp. 570-586.

Hopp W. J. and Spearman, M. L. (1993). Setting leadtimes for purchased components in assembly systems. IIE Transactions, 25, pp. 2-11.

Li, D. and O'Brien, C. (1999). Integrated decision modeling of supply chain efficiency. Int. J. Production Economics, 59 , pp. $147-157$.

Lin, Y., Ma, S., and Liu, L. (2006). A multi-period inventory model of component commonality with leadtime. IEEE International Conference on Service Operations and Informatics (SOLI), IEEE, pp. 352-357.

Ma, S. H., Wang, W., and Liu, L. M. (2002). Commonality and Postponement in Multistage Assembly Systems. European Journal of Operational Research, 142, pp. 523-538.

Melo, M. T., Nickel, S., and Saldanha-da-Gama, F. (2009). Invited Review: Facility location and supply chain management - A review. European J. Operational Research, 196, pp. 401-412.
Mohebbi, E., and Choobineh, F. (2005). The impact of component commonality in an assemble-to-order environment under supply and demand uncertainty. Omega, The International Journal of Management Science, 33, pp. 472-482.

Nonas, S. L. (2007). Finding and identifying optimal inventory levels for systems with common components, European Journal of Operational Research, p. Doi: 10. 1016/ j.ejor. 2007. 1008. 1045.

Sabri, E. H. and Beamon, B. M. (2000). A multi-objective approach to simultaneous strategic and operational planning in supply chain design. Omega, 28 (5), pp. 581598.

Snyder, L. V. (2006). Facility location under uncertainty: a review. IEE Transactions, 38, pp. 537-554.

Simchi-Levi, D., Kaminsky, P., and Simchi-Levi, E. (2000). Designing and Managing the Supply Chain: Concepts, Strategies and Case Studies. Irwin Mc-Graw Hill, Boston, MA.

Tang, O. and Grubbstroom, R. W. (2003). The detailed coordination problem in a two-level assembly system with stochastic leadtimes. International Journal of Production Economics, 81-82, pp. 415-429.

Weber C. A. and Current J. R. (1993). A multiobjective approach to vendor selection. European J. Operations Research, 68, pp. 173-184.

Yano, C.A. (1987). Stochastic leadtimes in two-level assembly systems. IIE Transactions, 19 (4), pp. 371-378.

Yosi A. Hidayat is a faculty member of the Department of Industrial Engineering, Faculty of Industrial Technology, InstitutTeknologi Bandung, Indonesia. She received his Doctoral degree from Hiroshima University.Her research interests include technology transfer and supply strategy in supply chain management. Her email address is $<$ yosi@mail.ti.itb.ac.id $>$

Katsuhiko Takahashi is a Professor at the Department of Artificial Complex Systems Engineering, Graduate School of Engineering, Hiroshima University. He received his Doctoral degree from Waseda University. His research interests include production system and supply chain management. His email address is $<$ takahasi@hiroshima-u.ac.jp>

Katsumi Morikawa is an Associate Professor at the Department of Artificial Complex Systems Engineering, Graduate School of Engineering, Hiroshima University. He received his Doctoral degree from Hiroshima University. His research interests include production planning, scheduling, and human-computer interactive systems. His email address is <mkatsumi@hiroshima-u.ac.jp $>$

Kunihiro Hamada is an Associate Professor at the Department of Social and Environmental Systems Engineering, Graduate School of Engineering, Hiroshima University. He received his Doctoral degree from the University of Tokyo. His research interests include system engineering, ship engineering, and marine engineering. His email address is <hamada@naoe.hiroshima-u.ac.jp $>$ 
Lucia Diawati is a faculty member of the Department of Industrial Engineering, Faculty of Industrial Technology, Institut Teknologi Bandung, Indonesia. She received her Doctoral degree from Keio University, Japan. Her research interests include management of technology and product design \& development. Her email address is <luci@ganesha.itb.ac.id, diawati@yahoo.com>

Andi Cakravastia is a faculty member of the Department of Industrial Engineering, Faculty of Industrial Technology, Institut Teknologi Bandung, Indonesia. He received his Doctoral degree from Hiroshima University. His research interests include supply chain management and management of technology. His email address is <andi@mail.ti.itb.ac.id> 